\title{
Modelling the effects of ionising radiation on a vole population from the Chernobyl Red forest in an ecological context
}

Vives i Batlle, J. $(\bowtie)^{1 *}$, Sazykina, T. ${ }^{2}$, Kryshev, A. ${ }^{2}$, Wood, M.D. ${ }^{3}$, Smith, K. ${ }^{4}$, Copplestone, D. ${ }^{5}$ and Biermans, G. ${ }^{6}$

${ }^{1}$ Belgian Nuclear Research Centre (SCK CEN), Boeretang 200, 2400 Mol, Belgium. Tel: +32 (0)14 3388 05, Fax: +32 (0)14 3210 56, e-mail: jordi.vives.i.batlle@sckcen.be

${ }^{2}$ Research and Production Association “Typhoon”, 4 Pobedy Str., Obninsk, Kaluga Region 249038, Russia

${ }^{3}$ School of Science, Engineering \& Environment, University of Salford, Manchester, M5 4WT, United Kingdom

${ }^{4}$ RadEcol Consulting Ltd., 5 The Chambers, Vineyard, Abingdon, OX14 3PX, United Kingdom

${ }^{5}$ Faculty of Natural Sciences, University of Stirling, Stirling, FK9 4LA, United Kingdom

${ }^{6}$ Federal Agency for Nuclear Control, Rue Ravensteinstraat 36, 1000 Brussels.

*The corresponding author dedicates this paper to the memory of his parents. 


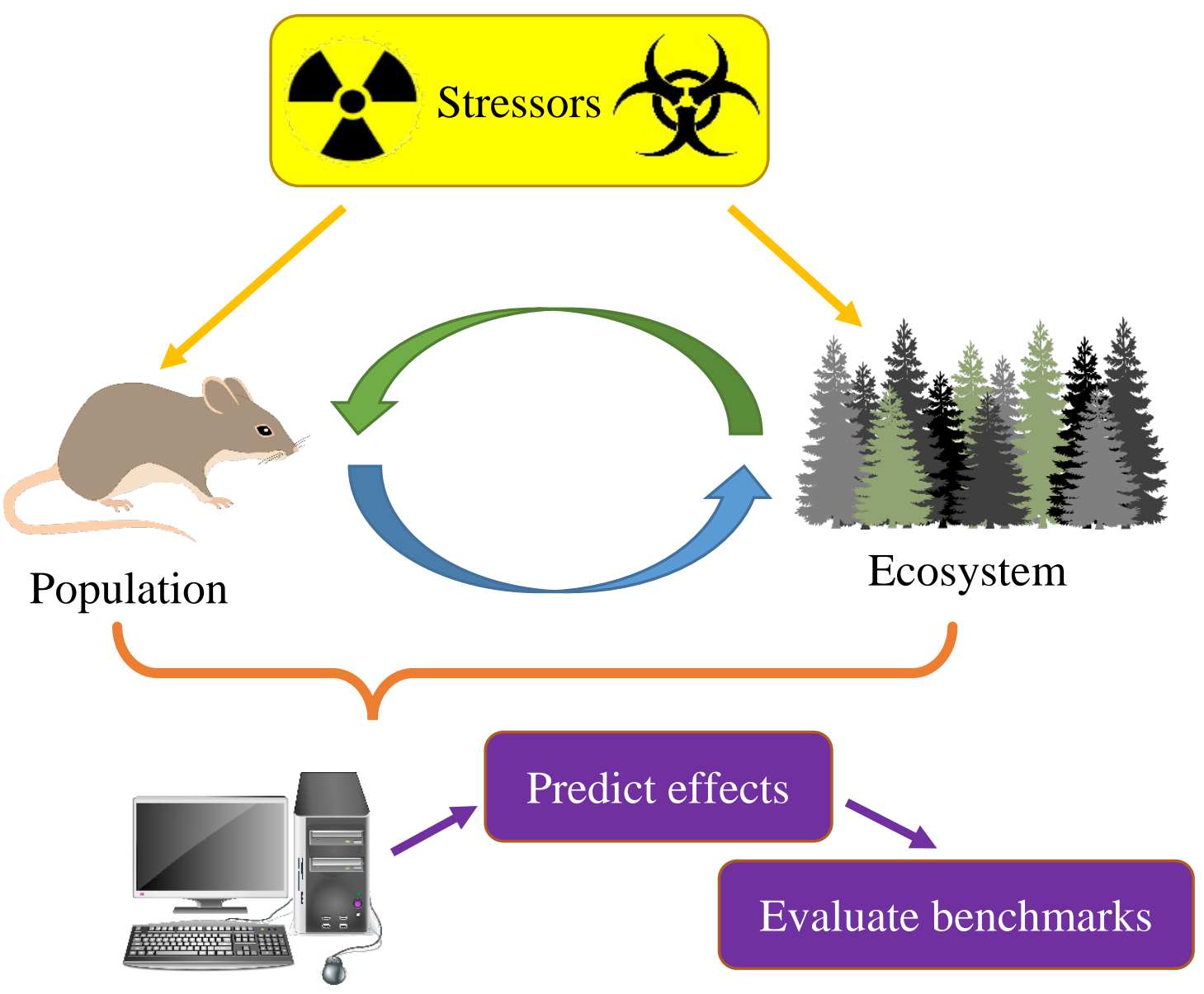




\section{Highlights}

Migration is effective in compensating for vole deaths at high levels of radiation exposure.

Long term effects simulated include a small historic dose component.

Adaptation can account for low dose radio-hypersensitivity and increased radio-resistance.

Current radiation dose assessment benchmarks are protective for the modelled vole population. 


\section{Abstract}

2 A novel mathematical model was developed to study the historical effects of ionising radiation from

3 the 1986 Chernobyl accident on a vole population. The model uses an ecosystem approach combining

4 radiation damages and repair, life history and ecological interactions. The influence of reproduction,

5 mortality and factors such as ecosystem resource, spatial heterogeneity and migration are included.

6 Radiation-induced damages are represented by a radiosensitive 'repairing pool' mediating between

7 healthy, damaged and radio-adapted animals. The endpoints of the model are repairable radiation

8 damage (morbidity), impairment of reproductive ability and mortality.

10 The focus of the model is the Red Forest, an area some $3 \mathrm{~km}$ west of the Chernobyl Nuclear Power

11 Plant. We simulated ecosystem effects of both current exposures and historical doses, including

12 transgenerational effects and adaptation. The results highlight the primary role of animal mobility in

13 stabilising the vole population after the accident, the importance of ecosystem recovery, the time

14 evolution of the repairing and fecundity pools and the impact of adaptation on population

15 sustainability. Using this model, we found dose rate tipping points for mortality and morbidity, along

16 with a limiting migration rate for population survival and a limiting size of the most contaminated

17 region needed not entailing loss of survival.

Our ecosystem approach to radioecological modelling enables an exploration of the impact of radiation in an ecological context, consistent with the available observations. Model predictions

21 indicate that population sensitivity in this exposure scenario does not contradict the benchmarks currently considered in risk assessments for wildlife. The model can be used to support advice on the extent to which historical doses and other ecological factors may influence different exposure modelling scenarios. The approach could easily be adapted to accommodate other stressors, thereby contributing to the evaluation of other regulatory benchmarks used in non-radiological risk

26 assessment. 


\section{Introduction}

28 Population modelling is well known in classical ecology (Lotka, 1925; Verhulst, 1838; Verhulst, 1845) and the potential role of these models in ecological risk assessment has been recognised (Galic et al., 2010). They have been used to investigate the impacts of chemical contaminants on wildlife (Forbes and Calow, 2002; Hanson and Stark, 2011; Ibrahim et al., 2014; Stark et al., 2004). Recently, population modelling has been introduced in the field of radioecology (Alonzo et al., 2016; Monte, 2009; Sazykina, 2018; Vives i Batlle et al., 2012). These models help researchers to explore the potential population level consequences of ionising radiation, but they are insufficient for informing regulatory decision making where an ecosystem approach is increasingly advocated (Bradshaw et al., 2014; Brechignac, 2009). We present here a new type of radioecological model considering the impact of radiation in an ecological context (e.g. resource availability, migration, spatial heterogeneity and the impact of historical doses) on a population of voles living in a radioactively contaminated area close to the Chernobyl nuclear power plant (ChNPP) in Ukraine, such as the field vole Microtus agrestis, the bank vole Myodes glareolus and other vole species.

\subsection{The 1986 Chernobyl NPP accident}

The ChNPP accident of 26 April 1986 remains the worst and most significant nuclear accident in history. Some $2600 \mathrm{~km}^{2}$ of Ukrainian territory around the ChNPP are officially designated as the Chernobyl Exclusion Zone (CEZ). Due to the levels of radioactivity in the CEZ soils (mainly ${ }^{137} \mathrm{Cs}$ but also ${ }^{90} \mathrm{Sr},{ }^{241} \mathrm{Am}$ and $\mathrm{Pu}$ - isotopes), the entire area is closed to the public. As a result of human removal, abundant fauna and vegetation have inhabited the region and the CEZ has become an area of high scientific interest for the study of radiation effects in wildlife.

An area of special interest near the epicentre of the accident is the Red Forest (Fig. 1), where the radioactive cloud killed Scots pines (Pinus sylvestris). Although there was clearing and burial of top soil in the Red Forest following the accident, it remains the world's most radioactively contaminated terrestrial ecosystem. Deciduous trees, which are more radio-resistant than pine trees, now provide the dominant tree cover in the Red Forest and the area supports a diversity of animal populations (Bird and Little, 2013). One of these is the vole, a herbivorous mammal approximately $10 \mathrm{~cm}$ in length, of the order Rodentia (Wood et al., 2009). Commonly found throughout the European continent, field voles inhabit humid grass environments such as woodlands, marshes and river margins (Kryštufek et al., 2008). Voles are an ideal bio-indicator to study the effects of environmental radiation in the Red Forest due to their ubiquitousness, proximity to ground (the main source of radioactive contamination) and relatively limited home range (Borowski, 2003).

It has been estimated that the absorbed dose rate to small mammals in the Red Forest decreased from an initial maximum of $6 \mathrm{~Gy} \mathrm{~h}^{-1}$ in 1986 to around $150 \mu \mathrm{Gy} \mathrm{h}^{-1}$ in 2005 (Gaschak et al., 2011). As of 2018, dose rates to wildlife from the Red Forest, estimated from measured organism and soil activity concentrations, were in the order of $20-150 \mu \mathrm{Gy} \mathrm{h}^{-1}$, specifically $48 \mu \mathrm{Gy} \mathrm{h}{ }^{-1}$ for vole species (Beresford et al., 2019). A double exponential representation of the dose profile in $\mathrm{Gy}^{-1}$ can be inferred, as $d_{r}(t)=144 e^{-\frac{1.1 t}{365}}+7.2 \times 10^{-3} e^{-\frac{0.05 t}{365}}$ where $t$ is the number of days since the accident. In this representation, 4500 days is the transition point $T_{S}$ where the short lived radionuclides have 
decayed sufficiently, so $95 \%$ of the dose rate is accounted for by the slow decaying term, $7.2 \times 10^{-3} e^{-\frac{0.05 t}{365}}$

Such dose rates exceed even now the dose rates below which populations are unlikely to be significantly harmed based on current knowledge (known as benchmarks). One such benchmark is the set of International Commission on Radiological Protection (ICRP) derived consideration reference levels, or DCRLs. DCRLs are bands of dose rate within which there is likelihood of deleterious effects of ionising radiation for Reference Animals or Plants (RAPs). These bands are currently set at 4-40 $\mu \mathrm{Gy} \mathrm{h}{ }^{-1}$ for mammal, bird and pine tree RAPs (ICRP, 2008). Another type of benchmark is the ERICA default screening dose rate, applicable to incremental (above background) exposures. This screening dose rate, as derived from species sensitivity distributions, is $10 \mu \mathrm{Gy} \mathrm{h} \mathrm{h}^{-1}$ (Brown et al., 2008).

Published data on actual radiation effects from the CEZ are controversial, with significant disagreement between researchers as to the extent to which wildlife has been affected (Beresford et al., 2020a). There are reports of increases in total wildlife abundance over time as humans left the area (Deryabina et al., 2015), and even reports of "beneficial” physiological effects in voles, such as increased resistance of fibroblasts from against oxidative and DNA stresses in bank voles (Mustonen et al., 2018). However, there is a consensus that, at the high dose rates present in 1986 (with monthly doses of $22 \mathrm{~Gy}$ for $\gamma$-irradiation and $860 \mathrm{~Gy}$ for $\beta$-), animals would have been negatively impacted.

Population declines in mammals (including voles) by the autumn of 1986 have been documented, with relatively quick recoveries by 1987 (Geraskin et al., 2008; Kryshev et al., 2005; Meeks et al., 2007; Testov and Taskaev, 1990). There are also reports of voles showing slight but significant increases in chromosomal aberrations, mitochondrial DNA mutations and cataracts, yet other work found no signs of genotoxic stress (Baker R et al., 2017; Lehmann et al., 2016; Rodgers and Baker, 2000; Ryabokon and Goncharova, 2006). In an attempt to address data deficiencies and discrepancies, projects COMET (EU) and TREE (UK) ${ }^{1}$ performed new field studies (Beresford et al., 2020b), compared results with biota dose assessment benchmarks (Brown et al., 2016; Brown et al., 2008; ICRP, 2008) and showed that external dose rates for radiocaesium often exceeds internal(Chesser et al., 2000), with effects occurring in the dose rate ranges expected.

\section{Objectives and hypotheses of the study}

The objective of this study was to model the effects of ionising radiation in voles from the Red Forest in their ecological context and to use this model for evaluating risk criteria (benchmarks) used in regulation. For this, we considered spatial influences (e.g. migration, inhomogeneity of contamination) and historical doses (higher exposure of previous generations), although we did not consider seasonal variations due to the large uncertainties induced in model parameterisation.

The emphasis of methodologies for the protection of the environment from radiation is to protect populations (rather than individuals) of flora and fauna, from the deterministic effects of radiation. Presently, population modelling is not included in regulatory assessments, so our intent was to

\footnotetext{
${ }^{1}$ https://radioecology-exchange.org/content/comet; https://tree.ceh.ac.uk/
} 
introduce the concept in the stakeholder dialogue on factors influencing wildlife population responses to radiation. The model presented here is therefore a simplified representation fit for that purpose. We wanted to capture an ecosystem approach in a compact set of equations that is as simple and practical as possible, requiring a less substantial investment for acceptance by regulators and stakeholders who wish to understand the key problem variables. Therefore, we intend this study to be used as a stable base for future development in the process of bridging the gap between science and application.

We focused this study on two questions: (a) what are the key ecological factors that, in combination with radiation sensitivity, determine the voles' vulnerability to radiation? and (b) what is the impact of previous 'acute' exposures on organisms? We hypothesised that animal movement between differently contaminated areas is a major influence on population stability at high doses of radiation, and that transgenerational effects such as adaptation are not so influential, but they can help to understand discrepancies between effects observed and predicted at low doses. An additional hypothesis was that the existing protection benchmarks for small mammals are fit for purpose in an ecological context.

\section{3. Model description}

123 The model is a semi-realistic representation of the voles' habitat comprising three abstract regions: the middle of the Chernobyl Red Forest (characterised by high dose rates), with an estimated surface area of $2.5 \times 10^{5} \mathrm{~m}^{2}$, a surrounding patch of $5 \times 10^{5} \mathrm{~m}^{2}$ with $10 \%$ of the dose of the previous region, and an external area with zero exposure. Region 3 could be very large, but for our purposes we define it arbitrarily as equal to Region 2 , or $5 \times 10^{5} \mathrm{~m}^{2}$, but connected to the external environment so voles from outside can migrate into the inner regions. Migration between patches are a function of differences in population density. Animals moving both ways between Regions 1 and 3 must pass through Region 2.

Voles can be in four states: healthy $(X)$, sick $(Y)$, adapted $(W)$ or dead $(Z)$. Radiation-sensitive, logistic auto-recoverable functions $F$ and $R$ exist for fecundity and radiation damage repair (Kryshev et al., 2006; Kryshev et al., 2008). Due to current lack of the necessary systematic knowledge, it is not possible to model each stage of the complex repair process, but this is not really necessary for our type of model, as we only aim to reproduce the qualitative behaviour of the system. Evidence for an adaptive response to chronic low-dose radiation at Chernobyl is somewhat equivocal (Møller and Mousseau, 2016), but there is some indication of such effect, as mentioned previously (Mustonen et al., 2018). Hence, the mechanism was introduced in our model, represented by a 'memory effect' in which successful repair occurs with a given probability (Section 3.5).

A summary of the model parameters as determined by literature review, best judgement and/or field observations, are shown in Table 1. This table gives the parametrisation of the model at the level of vole, as a complete set of parameters for a specific vole species is not available.

\section{3.1. Representation of the ecology}

146 Suitable literature was identified on vole range sizes. Range size is variable depending on habitat (as we know for other species) and that males range further than females (Borowski, 2003). As a first attempt, since there is no sex differentiation in the model, we assume that the range size is the average of the male and female range sizes for Birch woodland, or $510 \mathrm{~m}^{2}$. 
There are various studies for voles and similar rodents reporting population densities between 6 and 100 individuals ha-1 (Aulak, 1973; Borowski, 2003; Hutterer et al., 2016; Spitzenberger, 1999; Torre and Arrizabalaga, 2008), averaging to 34 individuals ha- ${ }^{-1}$. Seasonal variation is large, namely $10^{1}-10^{2}$ individuals ha $^{-1}$ (Wereszczyńska et al., 2007). Studies performed in bank voles and mice show fluctuations between lower values of 6-15 individuals/ha in spring (Jedrzejewska and Jedrzejewski, 1998) and 11-155 individuals/ha in autumn (Stenseth et al., 2002). However, we did not consider seasonal variations in density, given the large spread of the reported data and consequent uncertainty, and the fact that, although densities fluctuate from year to year, the long-term trend appears stable (Hutterer et al., 2016). Hence, we adopted an annual average of 37 individuals ha-1 ${ }^{-1}$ or $3.7 \times 10^{-3}$ voles $\mathrm{m}^{2}$ (Aulak, 1973; Borowski, 2003) for a deciduous woodland study is a reasonable starting point for our modelling. Region 3 is really pine forest and Region 2 has a mixed vegetation, but for simplicity we assume that all patches have the same maximum number of animals per unit area. Therefore, the maximum capacity of each patch would be 925, 1850 and 1850 voles for Regions 1 - 3, respectively.

Regions of finite sizes cannot sustain an infinite growth of the population; population growth is therefore modelled according to Verhulst's logistic equation (Verhulst, 1838; Verhulst, 1845), which in essence predicts that the rate of growth of a population of $N$ individuals follows the governing equation $\frac{d N}{d t}=r N\left(1-\frac{N}{K}\right)-d N$, where $r$ is the reproduction rate constant, $K$ is the carrying capacity, representing the maximum number of individuals (sum of $X, Y$ or $W$ ) that the ecosystem can support (and to which the model tends asymptotically with time) and $d$ is the natural death rate constant. In optimum conditions, $K$ is the surface area multiplied by the population density allowed by habitat quality in the absence of radiation, but in reality there are subtractive terms in above equation to account for mortality, predation, radiation damage etc., so the population grows to an asymptotic value below $K$.

This model could be improved by introducing a minimum number $\gamma$ below which the population cannot recover (for example 2, i.e. a single couple of male and female), and introducing an additional term to the growth part of the equation, such as $\frac{d N}{d t}=r N\left(1-\frac{N}{K}\right)\left(1-\frac{\gamma}{N}\right)$. Our model equations include this term, but we found no data on the minimum vole population that is genetically viable; hence we set $\gamma$ to 0 until more information is available.

The reproduction rate constant was calculated as follows. Voles have a high reproductive potential of between 4 and 5 litters per year, each one consisting of 3-5 (EOL, 2020), 4-7 (Glorvigen, 2012) and 5 (Sundell, 2002) young. Voles grow quickly with females maturing at 2-3 weeks and males maturing at 6-8 weeks ((MacDonald, 2001), cited in (EOL, 2020)). In order to approach the optimum reproduction rate, we selected the upper value of 35 voles per year $\left(0.10\right.$ days $\left.^{-1}\right)$. However, each newly born vole originates from a pair of breeding voles, so the rate constant should be corrected in order to obtain the mean per capita reproduction rate constant. The fraction of females in the population at birth is close to 0.5, but it becomes weighted to females as maturity approaches (Myllymäki, 1977). This is especially true at peak abundance, due to differential dispersal of the sexes. We derived a female fraction of $0.57 \pm 0.05$ for Microtus agrestis in Sweden in 1973, a year in which there was a 
population peak and so the effect is discerned with higher statistical significance (Hansson, 1978). Therefore, we adopted a population averaged reproduction rate constant of 0.06 days $^{-1}$.

The natural death rate constant was deduced from a 2-year study of a population released on an island in which the proportion of individuals surviving averaged to 0.54 (Boratyński and P., 2009). From this, a natural death rate constant of $6.3 \times 10^{-4} \mathrm{day}^{-1}$ could be assumed. However, this value does not include predation. A natural death rate constant (combining natural death and predation) of 0.0031 day $^{-1}$ (Sazykina and Kryshev, 2016) was therefore adopted, based on data from the AnAge database (AnAge, 2020). This means that some $80 \%$ of deaths are due to predation, and the death rate is a strong function of predation pressure (voles are an important part of the diet of barn owls and they are also preyed on by kestrels, other owls, weasels, stoats, foxes and snakes).

Whereas the reproduction rate changes with increasing population density following the logistic model (Verhulst, 1838; Verhulst, 1845), the death rate (and hence the predation rate) remains unaltered in our formulation. A formulation such as the Lotka-Volterra predator-prey model (Monte, 2009) is not used, because the model's intended purpose is to compare model output with the DCRL band of dose rate for a small mammal defined for the ICRP RAPs (ICRP, 2008), as seen in Section 4 on tipping points and the testing of benchmarks. Presently, the international system of radiological protection does not incorporate explicitly predator-prey interactions. Hence, we are making a compromise between factorising predation in a sufficiently simple model by means of a compound parameter (the total death rate constant) and more sophisticated models that would require many more site specific parameters and would not be necessary be fitter for purpose.

We introduced an additional layer of ecological realism in the model by making $K$ for the most contaminated patch variable, given that the resource in the ecosystem (vegetation) was initially damaged and recovered subsequently. To do this, we adopted a simple logistic equation for the carrying capacities of the three regions of the model, $K_{i}(i=1 \ldots 3)$ :

$\frac{d K_{i}}{d t}=K_{i}^{\max } \sigma_{i}\left(1-\frac{K_{i}}{K_{i}^{\max }}\right)-v_{i} d_{r i}$

The term $\delta_{i} D R_{i}$ in Eq. 1 is a linear dose-response relationship without threshold for the ecosystem. The parameter $K_{i}^{\text {max }}$ is the maximum carrying capacity (equal to surface area $S A_{i}$ multiplied by the optimum population density $\rho_{i}$ ). We used the same optimum density for all the patches. $d_{r i}$ is the dose rate constant and the $\sigma_{i}$ and $v_{i}$ are the rate constants for vegetation recovery and damage, respectively.

We parameterised Eq. 1 as follows. For $\sigma_{i}$ (taken to be the same in all regions) we assumed that a certain fraction $f$ of the vegetation has recovered exponentially after a time $\tau: f=1-e^{-\sigma \tau}$, and so $\sigma=\frac{1}{\tau} \ln \left(\frac{1}{1-f}\right)$. Assuming a 95\% recovery after half a year, $\lambda=\frac{2}{365} \ln \left(\frac{1}{1-0.95}\right)=0.0164 d^{-1}$. For $v_{i}$

230 (which has units of $\mathrm{Gy}^{-1}$, and is also assumed to be equal for all regions) we require the dose rate $d_{r}$ that kills a certain fraction $f$ of the population in a short exposure time $\tau$, so $v=\frac{\ln f}{d_{r} t}$. If the dose kills $50 \%$ of the population in 30 days, then $v$ must be of the order of $\frac{\ln 2}{L D_{50 / 30}}$. Since the grass understory is 
the relevant vegetation for voles, we used the mean $L D_{50} \mathrm{~S}$ of 16,20 , and $22 \mathrm{~Gy}$ for barley, wheat, and oats (all wild grasses), respectively (Real et al., 2004). This gives the conservative value $\delta=\frac{\ln 2}{19.33}=$ $0.036 \pm 0.006 G y^{-1}$.

There is further information on impacts of radiation on terrestrial biomass (Monte, 2009; Real et al., 2004; Sazykina and Kryshev, 2006; Sazykina and Kryshev, 2003; Whicker and Schultz, 1982a; Whicker and Schultz, 1982b). This should allow, in future work, to include additional refinements, such as that thinning-out of trees would have led to an increase in ground vegetation and hence potential food resource availability for voles.

It must be emphasised that Eq. 1 does not include vole avoidance reactions, that is, whether incoming voles have recognition of any problems with the area, such as by observing unoccupied and degraded nests and remains of their predecessors. This kind of effect is very complex to model, with no specific data available as yet for voles in the region considered.

\subsection{Representation of animal migration}

We adopted a simplified matrix-based representation in which migration rates from Region $i$ to Region $j$ are assumed to be proportional to the gradient of population density between regions. We also assumed that healthy, sick and adapted have equal mobility:

$M_{1}=$ Migration $_{2 \rightarrow 1}-$ Migration $_{1 \rightarrow 2}=\mu_{21} \frac{T_{2}}{S_{2}}-\mu_{12} \frac{T_{1}}{S_{1}}$

$M_{2}=$ Migration $_{1 \rightarrow 2}+$ Migration $_{3 \rightarrow 2}-$ Migration $_{2 \rightarrow 1}-$ Migration $_{2 \rightarrow 3}$

$$
=\mu_{12} \frac{T_{1}}{S_{1}}+\mu_{32} \frac{T_{3}}{S_{3}}-\mu_{21} \frac{T_{2}}{S_{2}}-\mu_{23} \frac{T_{2}}{S_{2}}
$$

$M_{3}=$ Migration $_{2 \rightarrow 3}-$ Migration $_{3 \rightarrow 2}=\mu_{23} \frac{T_{2}}{S_{2}}-\mu_{32} \frac{T_{3}}{S_{3}}+\phi_{0}$

Where $\mu_{i j}$ are the elements of the migration matrix for a patch of a specific surface area representing animal movement from Region $i$ to Region $j\left(i=1\right.$ to 3 - in units of $\left.\mathrm{m}^{2} \mathrm{~d}^{-1}\right)$ and $T_{i}=X_{i}+Y_{i}+W_{i}$.

\section{Consequently:}

$M_{i}=\sum_{j=1}^{3}\left(\mu_{j i} \frac{T_{j}}{S_{j}}-\mu_{i j} \frac{T_{i}}{s_{i}}\right)+\phi_{0} \delta_{i 3}$

259 If we assume that there is no preferential direction of travel, then the migration matrix is symmetrical $260\left(\mu_{i j}=\mu_{j i}\right)$. All diagonal matrix elements $\mu_{i i}$ have zero value.

261 The term $\phi_{0} \delta_{i 3}$ (where $\delta_{i 3}=1$ if $i=3$ and 0 if $i \neq 3$ ) is introduced to signify that Region 3 is an 262 unlimited source of animals, being connected to the outside world, so any loss or supply of individuals between region 3 and its neighbour Region 2 is by definition balanced by a supply or loss of individuals from outside. In our results, we made additional simulations for a Region 3 isolated from the outside world in order to investigate the impact of varying surface area in that region, as a form of sensitivity analysis. 
Mathematically, $\phi_{0}=-\sum_{j=1}^{3}\left(\mu_{j 3} \frac{T_{j}}{S_{j}}-\mu_{3 j} \frac{T_{3}}{S_{3}}\right)=\frac{T_{3}}{S_{3}} \sum_{j=1}^{3} \mu_{3 j}-\sum_{j=1}^{3} \mu_{j 3} \frac{T_{j}}{S_{j}}$ and $M_{i}=$ $\left(1-\delta_{i 3}\right) \sum_{j=1}^{3}\left(\mu_{j i} \frac{T_{j}}{s_{j}}-\mu_{i j} \frac{T_{i}}{S_{i}}\right)$. This means that, for Region 3, migration applies to $X, Y$ and $W$ whereupon it is apportioned to each category by a weighting factor: $M_{i}^{X}=\frac{X_{i}}{T_{i}} M_{i}$, a $M_{i}^{Y}=\frac{Y_{i}}{T_{i}} M_{i}$ and $M_{i}^{W}=\frac{W_{i}}{T_{i}} M_{i}$, respectively. This weighting is important: without it, mathematical asymmetries would be introduced in the model equations; migration must not depend on class of individual but on differences between total numbers of voles present in adjacent regions.

Eq. 2 above makes a simplification for Region 3, because migration from Region 2 to Region 3 gives rise to dilution of $Y$ and $W$ into an infinite pool and the migration back from Region 3 to Region 2 is considered to be solely of individuals of type $X$. The justification is that the proportion of $Y$ and $W$ in region 3 would be extremely low, given that it represents an infinitely large region where the dose rate is assumed to be zero. Hence, individuals born in that region are overwhelmingly of type $X$. Ultimately, calculation of population in region 3 is not directly relevant to our study, as this region acts merely as a reservoir.

280 Migration applies also to the quantities $F$ and $R$, since they are pools that "move" along with their carriers. It is assumed that they intermix with migrations $M_{R i}$ and $M_{F i}$ as function of fecundity and recovery, respectively, with the same migration matrix coefficients as for $M_{i}$; hence $M_{R i}=$ $\sum_{j=1}^{3}\left(\mu_{j i} \frac{R_{j}}{s_{j}}-\mu_{i j} \frac{R_{i}}{S_{i}}\right)+\phi_{0} \delta_{i 3}$ and $M_{F i}=\sum_{j=1}^{3}\left(\mu_{j i} \frac{F_{j}}{S_{j}}-\mu_{i j} \frac{F_{i}}{S_{i}}\right)+\phi_{0} \delta_{i 3}$. the migration matrix elements $\mu_{i j}$ in the above equation could not be found directly in the literature, nor could be measured, so we resorted to derive them indirectly by means of an additional, purposely developed random walk model. We assumed for simplicity that voles wander in a randomised walk pattern, starting with a population of 925 voles (indexed $i=1$ to 925 ) inhabiting a square patch of surface area $S_{1}=2.5 \times 10^{5} \mathrm{~m}^{2}$, and a carrying capacity of 925 inhabitants, in order to give the required density of 37 voles ha $^{-1}$. We set up a separate algorithm that calculated the initial coordinates of a random distribution of voles:

$x_{i, 0}=W\left(\rho-\frac{1}{2}\right), y_{i, 0}=L\left(\rho^{\prime}-\frac{1}{2}\right)$

Where $\rho$ and $\rho$ ' are random numbers between 0 and 1 . Note that this equation defines the origin of coordinates at the centre of the patch, so that the extremes of the calculated coordinates are $\left\{ \pm \frac{W}{2}, \pm \frac{L}{2}\right\}$.

294 At each time step $j=0$ to $\frac{T}{\Delta \mathrm{t}}$, defined in increments of $\Delta \mathrm{t}=0.01$ days for a total simulation of $T=1$ 295 day, the algorithm updates these coordinates:

$x_{i, j}=x_{i, j-1}+\left(\rho-\frac{1}{2}\right) \sqrt{2} v \Delta t, y_{i, j}=y_{i, j-1}+\left(\rho^{\prime}-\frac{1}{2}\right) \sqrt{2} v \Delta t$

297 Where $v$ is the velocity of the vole. Note that this equation is defined such that the maximum distance 298 walked by the vole (the modulus of the displacement vector) at each time step is, in Cartesian 299 coordinates: 
During each time step, the voles that cross a region border to emigrate are calculated as those which fulfil the following conditions: (a) that they were inside the patch at the previous time step, so $\left|x_{i, j-1}\right| \leq \frac{W}{\sqrt{2}}$ and $\left|y_{i, j-1}\right| \leq \frac{L}{\sqrt{2}}$, and (b) that they step out of the patch at the present time step, hence $\left|x_{i, j}\right|>\frac{W}{\sqrt{2}}$ or $\left|y_{i, j}\right|>\frac{L}{\sqrt{2}}$.The algorithm then counts the number of voles that remain in the region at each time step $t_{i}=i \Delta t$. The migration rate constant was then calculated by least-squares fitting of the function $m_{i}=\beta_{0} e^{-\beta_{1} t_{i}}$ where $\beta_{0}$ and $\beta_{1}$ are least squares best-fit parameters calculated by the algorithm, conform to the definition $\mu=\beta_{1} S_{A}$. The process was repeated 10 times and the results were averaged.

The key parameter in the above calculation is the average velocity $v$, which could not be found directly from literature. A study reports a mean daily-range size of field voles of $600 \mathrm{~m}^{2}$, and an interfix distance (the mean distance that the vole had moved between two consecutive fixes, used as a daily mobility index of voles) of about $10 \mathrm{~m}$ (Borowski and Owadowska, 2010). A previous study gives a daily interfix distance of $16 \pm 4 \mathrm{~m}$ (Koivula and Korpimäki, 2001), noting that this varies greatly, from 1 to $65 \mathrm{~m}$ per day. This is considerably lower than the mobility of larger mammals such as weasels and stoats, found to have daily ranges of $300 \mathrm{~m}$ and $1000 \mathrm{~m}$, respectively (Klemola et al., 1999).

Conversion of the interfix distance into a mean velocity was performed by extending our algorithm to calculate 100 vole trajectories starting from the same position at $\mathrm{T}=0$, allowing the animals to wander for 1 day. We obtained $v=200 \mathrm{~m} \mathrm{~d}^{-1}$ as the velocity required to obtain an average drift of $10 \mathrm{~m}$ after one day. This result was fed into Eqs. 4 and 5. The two-step stochastic algorithm approach to calculate the migration rates was implemented on an Excel VBA (Visual Basic for Applications) scripting code. The model as set up calculated, for 10 independent simulations, a mean $\mu_{i j}$ of $(3.7 \pm 0.5) \times 10^{5} \mathrm{~m}^{2} \mathrm{~d}^{-1}$.

\subsection{Approach for radiation damage and recovery}

The approach for assessing radiation damage and recovery is based on our previously published dual age class population model with radiation damage repair (Vives i Batlle, 2012). This model assumes a dynamic exchange between $X$ and $Y$ voles regulated by repairing and fecundity pools $R$ and $F$, respectively (Kryshev et al., 2006; Kryshev et al., 2008). $R$ represents the capacity to repair radiation damage of $Y$ to become $X$ again. Radiation dose causes a detriment in $R$, but $R$ can recover as a logistic function. If $R$ is depleted, more voles die. $F$ controls the reproduction of $X$ and is also affected by radiation, as well as being able to auto-recover logistically. The governing equations for radiation damage and recovery are given in Fig. 2.

The key parameters were determined by a deduction process (Kryshev and Ryabov, 2000; Kryshev and Sazykina, 2015; Kryshev et al., 2006; Kryshev et al., 2008; Sazykina and Kryshev, 2016; Sazykina and Kryshev, 2012), which we have incorporated into a previous model (Vives i Batlle, 2012). The parameter $\alpha=\ln (2) / L D_{50 / 30}$ controls the initial radiation damages $\left(\mathrm{mGy}^{-1}\right)$, and $\alpha_{f}$ describes damages to the reproductive system $\left(\mathrm{mGy}^{-1}\right)$. The time-dependence for mortality is due to damage to the haemopoietic system and consequential suppression of cell division leading to profound immunodeficiency, whereas damage to the reproductive system is mainly due to the sterilisation of stem cells for sperm production (oocytes tend to be more resistant). Stem cells for reproduction are more sensitive than stem cells that produce diverse lines lymphocytes and platelets, so it is generally 
assumed that $\alpha_{f}=10 \times \alpha$ (Kryshev et al., 2006; Kryshev et al., 2008). However, in our case, the parameter can be calculated directly from a reported dose threshold of $>4$ Gy causing $>90 \%$ organism sterility (Sazykina and Kryshev, 2016).

The rate constant for damages to repairing pool $\alpha_{r}\left(\mathrm{mGy}^{-1}\right)$ is derived from the same source. The parameters $\kappa$ and $\kappa_{r}$ (signifying recovery induced by the repairing pool) are assumed by the same study to be $\kappa_{R}=1.5 \times \kappa=1.5 / R_{\max }$. The Parameter $\mu_{r}$ is a conversion rate constant for sick individuals returning to a repaired state, and we gave it a value of 0.032 days $^{-1}$, as seen in Table 1 of a publication giving population sensitivities of animals to chronic ionising radiation (Sazykina, 2018). We chose the recommended parameter for mouse (Mus musculus) because this is a warm-blooded animal with a mass of $30 \mathrm{~g}$, similar to the vole, and this parameter value is thought to reflect best the fast metabolism of small mammals. A timescale of this order is plausible at least for males, due to cell division and repopulation of the spermatogonial stem cell pool. Lastly, $\varepsilon$ is derived from dose data for total lethality (Sazykina and Kryshev, 2016).

In the original model by Kryshev et al. (Kryshev et al., 2006; Kryshev et al., 2008) and our previous dual age-class model (Vives i Batlle, 2012), it was assumed that $Y$ do not reproduce. Here, we adopted a more realistic stance allowing reproduction of $Y$. We used a common $F$ and $R$ for all the categories of population, and a single overall carrying capacity $K$.

We avoided separate fecundities $F_{x}$ and $F_{y}$ for $X$ and $Y$ respectively, and hence $\mu_{\mathrm{x} / \mathrm{y}}$ and $r_{x / y}$ due to lack of realistic parameter data. Values of $F$ and $R$ for sick voles at different radiation dose rates are not readily available. With this simplification, the model cannot distinguish which organism is healthy and has full capacity to reproduce or self -repair, and which organism is sick and has these faculties depleted. In other words, the model captures these processes at the overall population level and not at the individual level. With this simplification, we can still represent at a phenomenological level generational damages whilst keeping at a minimum the number of model parameters.

A possible question is whether offspring from sick are themselves sick or are healthy, and whether the reproductive rate of the sick is lower. Our model is not an individual-based model, hence it cannot represent these features directly. However, these phenomena are indirectly captured because radiation depletes the repair pool, the fecundity pool is also depleted, so in practice populations with sick members have a corresspondingly calculated lower fecundity.

\subsection{Characterisation of the radiological exposure}

377 We adopted a dual exponential fitting for the dose rate received by the voles vs. time in $\mathrm{Gy} \mathrm{d}^{-1}$ : $d_{r}(t)=144 e^{-\frac{1.1 t}{365}}+7.20 \times 10^{-3} e^{-\frac{0.05 t}{365}}$ where $t$ is the time in days since the accident, based on (Gaschak et al., 2011). This function has two features: (i) a rapidly decreasing exponential term for the short-lived radionuclides that were significant contributors to dose in the initial period following the accident, and (ii) a slowly decreasing term to represent long-lived radionuclides $\left({ }^{137} \mathrm{Cs}\right.$ and ${ }^{90} \mathrm{Sr}$ ) (Monte, 2009). This approximation is valid because ${ }^{40} \mathrm{~K},{ }^{60} \mathrm{Co},{ }^{134} \mathrm{Cs},{ }^{154} \mathrm{Eu},{ }^{238,239,240} \mathrm{Pu}$ and ${ }^{241} \mathrm{Am}$ concentrations in soil were lower by 2-3 orders of magnitude than ${ }^{90} \mathrm{Sr}$ and ${ }^{137} \mathrm{Cs}$ (Gaschak et al., 2011). The bioavailability of actinides to small mammals is low (Beresford et al., 2016) and, at 
present, ${ }^{90} \mathrm{Sr}$ and ${ }^{137} \mathrm{Cs}$ are the main contributors to the total dose rate experienced by small mammals in the Red Forest (Beresford et al., 2019).

The model has an option to use a step function at the border between regions of high and low dose rate, and this was used in additional simulations with a constant dose rate over time (Section 3).

\subsection{Approach for modelling adaptation}

Effects studies indicating non-targeted effects such as adaptation as possible influences on the historical effects of radiation are still being critically evaluated. Consideration of adaptation in this model was introduced for exploratory purposes as a relatively simple phenomenological model, given that a population approach for the dynamics of cellular responses to radiation is already available (Wodarz et al., 2014). This model has a memory mechanism in which successful repair occurs with a probability 1 - $p$ and leads to adaptation with an average duration $1 / \eta$, and a communication mechanism under which an organism $Y$ can induce an organism $X$ to adapt with a rate proportional to $\beta_{0}$. An organism $W$ can also induce protection in an organism $X$ with a rate $\beta_{1}$, but this happens mainly in single cells rather than whole animals; hence we can assume $\beta_{0}=\beta_{1}=0$.

We adapted Wodarz's equations as such: $\frac{d X}{d t}=-\alpha d_{r} X+\eta W, \frac{d Y}{d t}=\alpha d_{r} X-c Y, \frac{d W}{d t}=(1-p) c Y-$ $\eta W$ and $\frac{d Z}{d t}=p c Y$, combining them with our general model by assuming that the outcome of the repair $(\kappa Y R)$ undergoes a branching between the formation of healthy voles, $\kappa Y R p$, and of adapted voles, $\kappa Y R(1-p)$, where $p$ is the probability of non-adaptation. Adapted individuals can in turn become healthy at a rate equal to $\eta W$. We also assumed that the repairing function is always 1 for $W$ organisms, since they are adapted to the radiation.

\section{The parameterisation of the adaptation sub-model for voles remains conjectural for now due to the} lack of observations. However, we used indirect information to infer some of the parameters. Intuitively, the adaptation rate constant should be slower than a fraction $f$ of the repairing pool recovery rate constant $\kappa$, hence $\kappa Y R(1-p)<f_{\kappa} Y R$ so $p>1-f$. Taking arbitrarily $\mathrm{f}=0.5$ gives $\mathrm{p}>0.5$.

The referenced adaptation study (Wodarz et al., 2014) states that at very low radiation doses ( $<0.3 \mathrm{~Gy}$ ) there is a hyper-radiosensitivity (HRS) phase. At slightly higher doses (0.5-1 Gy), an increased radioresistance (IRR) phase occurs. At higher doses ( $\gg 1 \mathrm{~Gy}$ ), the mechanism loses its effectiveness. This means that $p$ is dependent on cumulative dose, tending to diminish at high doses. Therefore, adaptation is more effective when a phase of low dose radiation (i.e. a 'priming' phase) occurs prior to a phase of higher dose radiation, somewhat reducing the overall susceptibility of the population or (in the case of an accident) when radiation levels have decreased enough for adaptation to begin.

We used a parametric saturation equation for $p$ as a function of dose, following the previous study (Wodarz et al., 2014) as $p(D)=\frac{p_{0}+p_{1} D}{1+p_{0}+p_{1} D}$, where $D=\int_{T-L}^{T} d_{r}(t) d t$, and $L$ is the relevant time of accumulation of the dose. It makes sense for $L$ to be, at least, a small number of generations (e.g. two). According to one study, the average lifespan for voles is $0.5-2$ years, with most individuals not lasting more than one breeding season (MacDonald, 2001); we therefore took 1 year as a reasonable estimate. 
Since the animals produce between 4 and 5 litters in the course of their lifespan, we assume that 0.5 years, rather than the full lifetime dose, is the relevant dose accumulation period $L$. The inevitable uncertainty in $L$ is not critical for short-lived animals (1 year) compared with the simulation timescale of some 35 years, for the most part giving lifetime doses far exceeding $1 \mathrm{~Gy}$.

In the study by Wodarz et al., the parameters $p_{0}$ and $p_{1}$ were set to $0.11 \pm 0.10$ and $0.023 \pm 0.017$, respectively, based on averages $(n=8)$ of best fittings to previously reported dose-response curves for HT29, HGL21, MR4, T98G and U138 cell lines (Krueger et al., 2007; Short et al., 1999a; Short et al., 1999b). It is debatable whether the values assigned to the parameters $p_{0}$ and $p_{1}$ are applicable to multicellular organisms, since they are for glioblastoma tumour cells, posing an unavoidable parametric uncertainty in the adaptation part of the model. The key difference is that whole organisms are longer-lived cell conglomerates and, as such, they are prone to absorb a higher dose during their lifespan compared with cells considered in isolation. Therefore, we assign values to the parameters $p_{0}$ and $p_{1}$ conjecturally, since they are (after all) probabilities for a mechanism operating at the cellular level, and we must await future experimental research to resolve the issue. The value of making this assumption now is that we can at least provide the mathematical mechanism to model adaptation and integrate it into our ecological population model, and although simulations are illustrative rather than predictive, this enables to set guidance for future model development.

For the rate constant of conversion of adapted to healthy cells ( $\eta$ ), the Wodarz et al. study uses a value of $0.01 \mathrm{~min}^{-1}=14 \mathrm{~d}^{-1}$. This is unlikely to be the same for whole animals, because in this case, one would expect animals to have complex defence systems that would slow down the loss of adaptation, in order to counteract their lower radio-resistance. Therefore, we expect $\eta<14 \mathrm{~d}^{-1}$ to be an upper 449 limit.

A very high dose of radiation would eliminate rapidly any of the few adapted individuals that formed very early (before the accumulated dose was too great). This means that, in our model, $\eta$ must exceed 0.08 days $^{-1}$, or else the number of $W$ would be sustained for the first 3 years after the accident, unlike observed. Our model gives a lower limit of $\eta=0.15$ days $^{-1}$ for $90 \%$ reduction of adapted organisms in the first 30 days. This value is intuitively correct, satisfying the conditions for a sharp drop in $W$ followed by a subsequent peak of 100 individuals after $900-2100$ days. This is consistent with reported observations of increased radio-resistance to super-lethal acute doses of $\gamma$-radiation in animals from the Kyshtym accident area for the $40^{\text {th }}$ generation of mice of mice living in radiation

459 biogeocenosis (Sazykina and Kryshev, 2006), because for voles, 40 generations is equivalent to 2550 460 days.

\subsection{Model equations and parameters}

The completed model was implemented in ModelMaker 4 (Adamatzky, 2001; Rigas, 2000), as shown time are: 
$\frac{d X_{i}}{d t}=-\left(\mathrm{d}_{i}+\alpha_{i} \mathrm{~d}_{r i}\right) X_{i}+\mathrm{p}_{i} \kappa_{i} Y_{i} \mathrm{R}_{i}+\frac{r_{i} X_{i}}{X_{i}+Y_{i}+W_{i}} \mathrm{~F}_{i}\left(1-\frac{X_{i}+Y_{i}+W_{i}}{\mathrm{~K}_{i}}\right)\left(1-\frac{\gamma_{i}}{X_{i}+Y_{i}+W_{i}}\right)+\eta_{i} W_{i}-\left(\beta_{0 i} Y_{i}+\right.$

$\left.\beta_{1 i} W_{i}\right) X_{i}+\frac{M_{i}}{T_{i}} X_{i}$

$\frac{d Y_{i}}{d t}=-\left(\mathrm{d}_{i}+\varepsilon_{i}\right) Y_{i}+\alpha_{i} \mathrm{~d}_{r i} X_{i}-\kappa_{i} Y_{i} \mathrm{R}_{i}+\frac{r_{i} Y_{i}}{X_{i}+Y_{i}+W_{i}} \mathrm{~F}_{i}\left(1-\frac{X_{i}+Y_{i}+W_{i}}{\mathrm{~K}_{i}}\right)\left(1-\frac{\gamma_{i}}{X_{i}+Y_{i}+W_{i}}\right)+\frac{M_{i}}{T_{i}} \mathrm{Y}_{i}$

$\frac{d W_{i}}{d t}=-\mathrm{d}_{i} W_{i}+\frac{r_{i} W_{i}}{X_{i}+Y_{i}+W_{i}} F_{i}\left(1-\frac{X_{i}+Y_{i}+W_{i}}{\mathrm{~K}_{i}}\right)\left(1-\frac{\gamma_{i}}{X_{i}+Y_{i}+W_{i}}\right)-\eta_{i} W_{i}+\left(\beta_{0 i} Y_{i}+\beta_{1 i} W_{i}\right) X_{i}+$

$\left(1-\mathrm{p}_{i}\right) \kappa_{i} Y_{i} \mathrm{R}_{i}+\frac{M_{i}}{T_{i}} \mathrm{~W}_{i}$

$\frac{d z_{i}}{d t}=\mathrm{d}_{i}\left(X_{i}+Y_{i}+W_{i}\right)+\varepsilon_{i} Y_{i}$

472

$\frac{d F_{i}}{d t}=r_{i} \mathrm{~F}_{i}\left(1-\frac{F_{i}}{\mathrm{~K}_{i}}\right)-r_{i} \mathrm{~F}_{i}\left(1-\frac{X_{i}+Y_{i}+W_{i}}{\mathrm{~K}_{i}}\right)-\alpha_{f i} \mathrm{~d}_{r i} F_{i}+M_{F i}$

473

$\frac{d R_{i}}{d t}=\mu_{r i} R_{i}\left(1-\frac{R_{i}}{\mathrm{~K}_{i}}\right)-\kappa_{r i} Y_{i} \mathrm{R}_{i}-\alpha_{r i} \mathrm{~d}_{r i} R_{i}+M_{R i}$

475

476

477

478

479

480

481

482

483

484

485

486

487

488

489

490

491

492

493

494

495

496

497

498

499

500

501

502

Where $X_{i}, Y_{i}, W_{i}, Z_{i}$ are the healthy, sick, radiation-adapted and dead individuals at Regions $\mathrm{i}=1,2$ and 3; $F_{i}$ and $R_{i}$ are the (dose-dependent) fecundity and radiation damage repairing functions, the migration fluxes $M_{i}$ are given by Eq. 2, $d_{r}(t)$ is the dual exponential fitting to the dose rate, and the time-dependent carrying capacity $K_{i}$ is given by Eq. 1 , with initial value $K_{i}^{\max }=S A_{i} \omega_{i}$ with $S A_{i}$ and $\omega_{i}$ being the surface area and the ideal population density of the three geographical patches, respectively. It is easy to check that if reproduction ceases, the model is mathematically in mass balance, since the $\operatorname{sum} X_{i}+Y_{i}+W_{i}+Z_{i}$ is constant.

A stable solution for the model for the case of no radiation or migration can be calculated by setting all the derivatives and all $d_{r i}$ to zero, whereupon $Y_{i}=W_{i}=0$ and $X_{i}=T_{i}$ are constant. If we further simplify by assuming $\gamma_{i} \ll X_{i}$ then we have $X_{i}=F_{i}=K_{i}\left(1-\frac{\mathrm{d}_{i}}{r_{i}}\right)$ and $R_{i}=K_{i}$. which can be retrofitted to the model as an approximation to initial conditions along with $\gamma_{i}=S A_{i} \omega_{\min }$ where $\omega_{\min } \geq 2$ and the initial conditions $Y_{i}(0)=W_{i}(0)=0$. As for the total population, assuming that $\gamma_{i} \ll X_{i}, \frac{d T_{i}}{d t}=$ $-\mathrm{d}_{i} T_{i}-\varepsilon_{i} Y_{i}+r_{i} \mathrm{~F}_{i}\left(1-\frac{T_{i}}{\mathrm{~K}_{i}}\right)+M_{i}$. This can be used to show that, if $d_{i}<<r_{i}$, the model solution is relatively insensitive to variability in $r_{i}$. In our model, for example, $d_{i} / r_{i}=3.1 \times 10^{-3} / 6 \times 10^{-2}=5 \times 10^{-2}$, whereupon $X_{i}=0.95 K_{i}$. Reducing $r_{i}$ by $50 \%$ would give $X_{i}=0.90 K_{i}$, causing only a $5 \%$ difference in model output for the case considered.

\section{Results and discussion}

The model equations were solved numerically from within the ModelMaker 4 software. The time step was set to 1 day. The simulation length was set to $10^{4}$ days, covering the initial phase of the accident and its long-term aftermath, given the time passed since the event. We used the Runge-Kutta solving algorithm with an accuracy of $10^{-5}$ and a minimum value of $10^{-11}$. The model output was checked for mass balance and found to be correct in this respect. The solution accuracy was checked explicitly against algebraically-derived approximate solutions.

\section{Healthy organisms: Fig. 4a shows an initial fall of $X$ in Region 1 . At this point, there are limited} resources available for the voles. Migration from patch 2 into 1 begins to occur with new arrivals 
becoming sick. As radiation decreases, more voles move into Patch 1 from 3, which acts as a donor

504

505

506

507

508

509

510

511

512

513

514

515

516

517

518

519

520

521

522

523

524

525

526

527

528

529

530

531

532

533

534

535

536

537

538

539

540

541

542

543

544

545

546 compartment, through 2, which acts as a transit compartment. Fig. 5 confirms this increased inward migration, peaking at 15 voles day ${ }^{-1}$ in Region 1 and 10 voles day $^{-1}$ in Region 2, respectively. The cause of this is a steep gradient of population density after the initial irradiation. After $3000 \mathrm{~d}$, net immigration declines sharply as the dose rate diminishes and population gradients tend to zero.

The initial dose rate (about $6 \mathrm{~Gy} \mathrm{~h}^{-1}$ ) is so high that it reduces $X$ in Region 1 to less than 3 individuals in just one day, turning them into $Y$. The original population from this Region would have rapidly disappeared (allometrically derived $L D_{50}$ for voles $\approx 6$ Gy (Bytwerk, 2006)) but for immigration from the adjacent regions, which causes a build-up to begin after 150 days. Initially, newly immigrated individuals become sick as soon as they enter Region 1. By 800 days, $X$ begins to increase as radiation decreases, overtaking $Y$ after 900 days. In Region 2, Fig. 4b, after an initial drop of healthy voles to 300 in 4 days, they begin to recover reaching 1000 voles at $\mathrm{t}=90$ days. Henceforth, $X$ in Regions 1 and 2 recover steadily. Region 2 reaches $90 \%$ of the initial model value of 1750 voles after 1000 days. Region 1 recovers more slowly, reaching 90\% of the initial model value of 877 voles after 1670 days. Thus, from 1700 days, $X$ is restored, sustained by immigration. Fig. $4 \mathrm{~b}$ shows that, by $\mathrm{T}=10000$ days, adaptation does not significantly influence the results; hence, immigration from less contaminated areas is the responsible agent for recovery in our model, offsetting losses by radiation damage.

Ecologically speaking, voles would only move into a contaminated area if there was a food or habitat resource that they could utilise, so it depends on a suitable habitat existing throughout in Region 1. The vole diet consists of leaves, seeds, grains nuts and fruit, some of which would have been available as understory vegetation began to regrow. Incoming voles would still be exposed to harmful dose rates, so population recovery by immigration would have been slow to begin with. Our model can capture this implicitly with the very simple Eq. 1.

We performed sensitivity analysis on the immigration rate, as shown in Fig. 6. By parameter variation, we obtained that if the migration matrix elements are reduced by a factor of $8 \times 10^{-4}$ (equivalent to 290 $\mathrm{m}^{2} \mathrm{~d}^{-1}$ ), then $X$ in Region 1, Fig. 6a, are still able to recover after 2800 days, when dose rates in Region 1 reach $0.035 \mathrm{~Gy} \mathrm{~d}^{-1}$. At $255 \mathrm{~m}^{2} \mathrm{~d}^{-1}$ at $0.035 \mathrm{~Gy} \mathrm{~d}^{-1}$ however, there is a tipping point for $X$ in Region 2 (Fig. 6b). In region 2 which is receiving $10 \%$ of the dose rate, there are no observable differences between the two migration rates, and $X$ is able to recover in both cases (Fig. 6c).

Sick organisms: As stated previously, most $X$ in Region 1 (and to a lesser extent in Region 2) become sick in the days after the accident. In region 1, Fig. 4a, this takes the form of a shallow peak with a maximum of 850 individuals in 56 days. $Y$ remains high ( $>800$ ) until $\mathrm{T}=800$ days. By 900 days, $Y$ are overtaken by $X$, and collapse in 1600 days. In Region 2, Fig. 4b, a peak of 400 sick voles is reached at 90 days, decreasing by $50 \%$ at 200 days and becoming exhausted after 960 days. This behaviour is explained by the time evolution of $R$ as shown in Fig. 7a: Initially, $R$ is zero. Whilst it increases quickly for Region 2, in the case of Region 1 there is no significant restoration of $R$ until after 1000 days, at which point recovery in Region 2 has already risen to $15 \%$ of its full value. Thus, animals in region 2 are already self-repairing whilst they cannot do so in Region 1 . A dose rate of $>7$ $\mathrm{Gy} \mathrm{d}^{-1}$ induces the collapse of $R$ in Region 1 at $\mathrm{T}=1000$ days, and a dose rate of $10 \mathrm{~Gy} \mathrm{~d}^{-1}$ at $\mathrm{T}=90$ days causes a minimum of the recovery pool at $0.8 \%$ of its initial value. Therefore, a dose rate of 7 - 
$10 \mathrm{~Gy} \mathrm{~d}^{-1}(5-7 \%$ of the initial dose rate at $\mathrm{T}=0$ days), typical of conditions in Region 1 some 900 1000 days after the accident or of Region 2 at about 120 - 240 days, is a tipping point for $R$ in both compartments.

At 4000 days, the dose rate to the voles is around $0.005 \mathrm{~Gy} \mathrm{~d}^{-1}=200 \mu \mathrm{Gy} \mathrm{h}^{-1}$ and the dose profile begins to settle into a slower exponential decrease. The population in Region 1 has approached stability and $R$ for Regions 1 and 2 are very close to equilibrium (see below). By the end of the simulation, with a dose rate of $40 \mu \mathrm{Gy} \mathrm{h} \mathrm{h}^{-1}=0.001 \mathrm{~Gy} \mathrm{~d}^{-1}$, there is no further redistribution between $X$ and $Y$. For comparison purposes, $200 \mu \mathrm{Gy} \mathrm{h}^{-1}$ corresponds to the middle of the intermediate DCRL band for amphibians and grass, and $40 \mu \mathrm{Gy} \mathrm{h} \mathrm{h}^{-1}$ is the upper DCRL for mammal, bird and, pine trees (ICRP, 2008).

Our model simulations show no difference in repair (and fecundity) when considering or not considering adaptation in Region 1, and the same for Region 2, simply because the equation of recoveries for $R$ (and $F$ ) are independent from adaptation processes, hence $F$ and $R$ for the case of no adaptation are not shown in Fig. 7. Although not shown in the figures, for the case of no migration, we found that $R$ is at optimum value for Region 3 but is obliterated for Regions 1 and 2. The situation for zero radiation is a trivial case, with all pools at carrying capacity.

Fecundity: The time evolution of $F$ is also given in Fig. 7. Initially, $F$ in Region 1 collapses (Fig. 7a) but it begins to recover almost immediately, whereas $R$ stays impaired for 1000 days. This is because our model assumes that $Y$ are able to reproduce, and the balance of high exposure and immigration from Region 2 into 1 conspire to maintain a reproducing sick population. In our previous modelling studies we showed that, for isolated populations, fecundity is a more sensitive endpoint than morbidity (Vives i Batlle, 2012; Vives i Batlle et al., 2012). For Region 2, Fig. 7b, there is an initial 90\% loss of fecundity which recovers by $\mathrm{T}=4000$ days. Henceforth, fecundity in both regions stabilises. In other words, after 5 years voles in Region 1 reproduce near to optimum levels, coinciding with dose rates of $0.1 \mathrm{~Gy} \mathrm{~d}^{-1}=4000 \mu \mathrm{Gy} \mathrm{h} \mathrm{h}^{-1}$.

Adaptation: $W$ form shortly after the beginning of the simulation, as soon as organisms begin to accumulate enough dose to trigger it, but the effect is short-lived due to the immediate build-up of cumulative dose (see Section 2.5). For Regions 1 and 2, Fig. 4a and 4c, the fraction of $W$ at $\mathrm{T}<1$ day was $22 \%$ and 50\%, respectively. Then, $W$ in Region 1 reach a minimum at 150 days, from whence they increase to form a broad peak with a maximum of 95 voles at $\mathrm{T}=1225$ days. $W$ remain at $>50 \%$ of this value from 875 to 2300 days, coinciding with cumulative doses of 2500 - 35 and 250 - 3.5 Gy, respectively, in Regions 1 and 2. The probabilities of adaptation at these levels of cumulative dose are $0.017-0.52$ and $0.14-0.84$, respectively. Taken together, this implies that most $W$ in Region 1 at that time come from Region 2, which has reached the IRR phase (see Section 2.5). Fig. 4c shows that $W$ in Region 2 also form a broad peak at this significant time interval (maximum of $10 \%$ of initial voles adapted at $\mathrm{T}=385$ days).

Both peaks of $W$ in Regions 1 and 2 subsequently fall, even though the probability of adaptation for Regions 1 and 2 is 0.9 after 4000 days (Fig. 8a), coinciding with dose rates of $5 \times 10^{-3} \mathrm{~Gy} \mathrm{~d}^{-1}$ (200 $\mu \mathrm{Gy} \mathrm{h}^{-1)}$ in Region 1 and $10 \%$ of that in Region 2, and cumulative doses of 1 and $0.1 \mathrm{~Gy}$, respectively. 
The cause for the fall in $W$ is that the proportion of $Y$ decreases as dose rate decreases, and our model does not consider adaptation from $X$. In addition, $W$ gradually return to their normal healthy state. We found no information to deduce if adaptation from healthy is ecologically significant at low doses (presently the model has $\beta_{0}=\beta_{1}=0$ due to lack of data).

Fig. 4b shows minor impact of adaptation on population sustainability. Some $10 \%$ of $Y$ become adapted in 875 - 2300 days, reducing the overall population morbidity, but these voles would be in the healthy group if adaptation were not considered. We cannot draw strong conclusions on whether adaptation can protect a population from extinction for the current scenario since the effect is masked by migration. As we refine adaptation modelling with data from planned field experiments, its significance may be further assessed. However, the example from Fig. 6a suggests that for species with a low migration capacity compared with voles, adaptation may be more significant. Examples would be ground-dwelling invertebrates and vegetation for which models are needed.

Effect of area size: We considered the consequences of the finite size of a Region 3 open to unlimited exchange with the outside world. This assumption is mathematically equivalent to a large, closed Region 3, provided its area exceeds 40 times that of the current Region 3 (equivalent to 25 times that of Regions 1 and 2 combined), because then the population can be sustained by migration of voles born in that outer area. A small and relatively uncontaminated area of $20 \mathrm{~km}^{2}$ with an autochthonous population of healthy voles is therefore enough to sustain the populations in the inner regions at the radiation levels considered. There is more than enough vegetation around the Chernobyl Red Forest to justify this assumption, since the area is surrounded by several kilometres of countryside comprising coniferous plantation, deciduous forest, abandoned farm lands and even some wetlands. Another way to interpret the above information is that, for the scenario considered, the contaminated part of a heterogeneously contaminated patch should be in a ratio of 1:25 or less with respect to the total area.

Tipping points and the testing of benchmarks: As shown in our previous studies (Vives i Batlle, 2012; Vives i Batlle et al., 2012), this type of radiation damage and repair model has tipping points around which benchmarks can be verified for protection of a population. Even if migration is considered, the model has tipping points, albeit at higher radiation levels. We performed a series of model simulations with a constant dose rate over time, varying that dose rate in order to find general tipping points for population at different levels of exposure. The results are shown in Figs. 9 (population) and 10 (repair pool and fecundity). We discuss only Region 1, as Region 2 is the situation for $10 \%$ of the Region 1 dose rate.

At dose rates coinciding with the lower and upper limits of the DCRL for small mammal (rat), namely $10^{-4}$ and $10^{-3} \mathrm{~Gy} \mathrm{~d}^{-1}$ (ICRP, 2008), no effects on population or recovery are predicted, irrespective of migration, and both fecundity and the repair pool are at optimum levels. Thus, for our simulated vole population, both the ICRP DCRL for small mammal - rat (4-40 mGy d $\left.{ }^{-1}\right)$ and the IAEA's maximum allowable dose rate for populations of wild mammals of $1 \mathrm{mGy} \mathrm{d}^{-1}$ (IAEA, 1992) are found to be protective of the population.

At an order of magnitude higher in dose rate $\left(10 \mathrm{mGy} \mathrm{d}^{-1}\right)$ minor effects are predicted as a very small number (ca. 5) of adapted organisms are formed. At this dose rate, species survival is not 
compromised however. The pools $R$ and $F$ are not significantly altered if migration is considered, but the first indications of morbidity and reproductive effects appear if migration is set to zero (some $15 \%$ loss of repairing ability and $10 \%$ loss of fecundity in Region 1). Previous studies report that radiation doses exceeding $10 \mathrm{mGy} \mathrm{d}^{-1}$ can begin to disrupt reproductive functions of animals (Gaychenko, 1995; Suschenya et al., 1995; Suschenya et al., 1990).

At $100 \mathrm{mGy} \mathrm{d}^{-1}$, the overall population is still unaffected if migration is considered, but the proportion of $W$ increases further to 20 animals in Region 1. Detriments of $5 \%$ and $10 \%$ in $R$ and $F$, respectively, appear at this dose rate. This is in line with previous investigations that, from above-background to $100 \mathrm{mGy} \mathrm{d}^{-1}$, genetic effects in sexual and somatic cells of small mammals have been recorded (Goncharova et al., 1999; Pomerantseva et al., 2006). If migration is excluded then $X$ collapse and $Y$ peak at 230 individuals at 135 days, overtaking $X$ at 170 days. Finally, the population in Region 1 collapses by $\mathrm{T}=650$ days. Both $R$ and $F$ fall precipitously; $R$ is virtually extinguished by $\mathrm{T}=50$ days and $F$ follows suit at 300 days. This aligns with data that only chronic doses exceeding $100 \mathrm{mGy} \mathrm{d}^{-1}$ are capable of causing a significant increase in the mortality rate of small mammals (Chesser et al., 2000; Pryakhin et al., 2002; Sokolov et al., 1994; Suschenya et al., 1995). owever, migration can offset effects at this level of dose. In general, migration delays the onset of effects by an order of magnitude of the dose rate.

The finding that the population collapses at $0.1 \mathrm{~Gy} \mathrm{~d}^{-1}$ without migration is not surprising, given that the model uses $\alpha=\ln (2) / L D_{50 / 30}$ with an $L D_{50 / 30}$ of 6.2Gy for mouse (Sazykina and Kryshev, 2016). At $0.1 \mathrm{~Gy} \mathrm{~d}^{-1}$, this dose would be delivered in 62 days. The population model predicts a collapse at 135 days (cumulative dose 13.5 Gy). Protraction of dose over timescales sufficient for multiple cycles of cellular reproduction therefore tends to increase the "apparent” value of the $L D_{50 / 30}$.

At $1000 \mathrm{mGy} \mathrm{d}^{-1}$ and with migration, the population is visibly compromised. More than 100 individuals (12\% of the initial population) are sick, half of $R$ is lost and there is a $40 \%$ loss of $F$. If migration is excluded, the healthy disappear to $<10 \%$ of its initial size over 70 days, and the sick in 390 days. $R$ collapses in 5 days and fecundity in 15 days. Lastly (not shown) the population disappears between $10-100 \mathrm{~Gy} \mathrm{~d}^{-1}$ even with migration (this is equivalent to the initial dose rate to the voles in our simulation).

Comparison with published results indicates that our model gives sensible answers, providing a point of validation. We also compared our findings with a previous model to model inter-comparison of radiation effects in populations (Vives i Batlle et al., 2012). For mice, the previous study reported population survival at $10^{-2} \mathrm{~Gy} \mathrm{~d}^{-1}$, followed by a sharp decrease in survivors between 0.02 and $0.03 \mathrm{~Gy}$ $\mathrm{d}^{-1}$ over a simulation period of 5 years. With migration disabled (to better compare with the simulations of the previous study), our model predicts population extinction in 1300 days (3.6 years) at $0.06 \mathrm{~Gy} \mathrm{~d}^{-1}$, within $<2$ of the inter-comparison result but in the same interval of $10^{-2}-10^{-1} \mathrm{~Gy} \mathrm{~d}^{-1}$, providing an additional degree of validation for our approach.

Historical dose effect: Several phenomena reported here occur with a time delay with respect to exposure: (a) nearly all $X$ become $Y$ initially, and $Y$ die out fast, but after the dose rate has decreased sufficiently, $Y$ and $W$ begin to form in Region 1 and they peak at 56 and 1221 days, respectively; (b) In 
Region 2, $Y$ and $W$ peak at 90 and 390 days, respectively (although this is not easily visible in Fig. 6, it can be seen in the data). These are examples of historical effects, appearing as they do months and, in some cases, years after peak exposures. The historical effects predicted are relatively small in comparison with current total population levels, but in a field situation, depending on the type of sampling (particularly if sick animals are oversampled, as they may be easier to catch) they point at potential miss-association of effects from the initial exposure to current (and lower) exposures.

To illustrate this, we conducted a theoretical simulation with the same starting population size but using a step-function of the dose rate, set to be equal to $25 \mathrm{~Gy} \mathrm{~d}^{-1}$ over 30 days, and $10 \mathrm{~Gy} \mathrm{~d}^{-1}$ thereafter. Results are shown in Fig. 11. In this abstract scenario, after transition to the lower dose rate, $Y$ actually increase from 320 at 30 days to a peak of 420 at 180 days, with $X$ reduced to $44 \%$ and a shallow secondary peak of 70 adapted voles forming after 225 days. If radiation had been maintained at $10 \mathrm{~Gy} \mathrm{~d}^{-1}$, then the model does not predict the peaking of $Y$ and $W$ but instead it predicts that these sub-populations change monotonically. The two simulations stabilise to the same end level.

This result shows that phenomena that depend on achieving a certain cumulative dose rather than dose rate, like adaptation, will generally manifest with a time delay. The peak of $Y$ also manifests as a "memory" effect in the system.

\section{5. Future model development}

696 The model presented here is a simplified representation fit for the purpose of exploring issues relevant to the current environmental radiological protection system. The equations provided are relatively simple and practical. They can be solved numerically with relatively simple computational resource, and partial analytical solutions can be explored for certain specific cases. Based on the present study, we can already foresee improvements to add more realism to the model.

Our model presumes that the migration rates for the various populations $X, Y$ and $W$ are equal. A more general type of model could be developed, in which the distinct populations of $X, Y$ and $W$ have different mobility. This would have the benefit of generality, so that cases could be explored in which these rates are varied. However, this would require knowledge of the differential migration rate constants of sick and adapted individuals, which is not provided for by current field studies.

Although the random walk model presented in this paper is a useful first step, the Monte Carlo approach could be extended to encompass a system in which females disperse more slowly than males. It should be kept in mind that male voles maintain a territory and defend it by expelling other males from it, whilst females just have a home range which may overlap with that of a neighbour. After leaving the nest, young female voles remain in or near their mother's home range, but young males are forced to disperse by the aggressiveness of the adult males. Female voles sometimes spontaneously move in the time gap between weaning one litter and producing the next, a phenomenon typical of this species. Hence, a modified algorithm that takes this into account would give an improved representation of the dispersion.

718 Adaptation of animals to radiation may require more detailed consideration in future modelling investigations than given here. This is because adaptation as a phenomenon may represent various 
processes, such as stimulation of DNA repair or partial synchronisation of the cell cycle. It is possible that the effect may depend more on dose rate than it is assumed here. It is still not fully clear how important this process is in a slowly declining spatially heterogeneous dose field, whether adapted individuals would revert to the healthy phenotype or whether the adapted state would persist. Additionally, it is necessary to determine empirically the probability of adaptation as a function of radiation dose for multicellular organisms.

Similarly, the spatial element of our model could be further developed. Our current model calculates overall population movement, but it cannot predict a reduction of the overall population drift due to the amount of time individuals are not moving when feeding/sleeping/mating, etc. It is mainly the younger voles that will migrate in order to find new territories and this is different to the general movement to find food within the home range. Moreover, in general, the dose rate pattern in any geographical region is heterogeneous and anisotropic rather than a simple set of radially interconnected regions. Therefore, it would be useful to explore a more complex pattern of connectivity between the differently contaminated regions, although this would tend to make the model less generic and more case specific.

The model could be further developed to add more ecological realism. Possible extensions include considering in detail seasonality, sex ratio and predator-prey interactions as explored in our previous work (Doi et al., 2005; Wilson et al., 2010). This would enable a more explicit behaviour of populations of voles and their predators in the wild, both generally and at Chernobyl.

A more realistic and detailed treatment would eventually require a Monte Carlo simulation of the whole system, facilitating further the model's application in evaluations of radiation exposure in heterogeneously contaminated landscapes (Aramrun et al., 2019). It is also possible to obtain, within an individually-based (IBM) type of model, population effects arising as emergent properties from what happens to individuals. Such a model would allow individuals of different ages coexisting, aging-related death to be accounted for and predation to be modelled as chance encounters between predators and their prey. Sex differences could be factorised, and inherited effects could be tracked over different generations. In addition, it would be possible to distinguish between individual animals that have received a potentially fatal dose but may recover, and animals that have received a sub-fatal dose and are likely to recover, but with reduced or completely suppressed capability to breed. This distinction would be useful because sterilised animals can continue to compete for fertile mates, whereas animals that have received a fatal dose are soon eliminated from the population. An IBM type of model would have the additional advantage of explicitly considering the fecundity and repair state of all individuals over time.

However, IBM modelling is complex and computationally demanding, in comparison with the ODE model developed here. Our approach is fit for current purposes, because the stated protection goal of radiation protection of the environment is the protection at the population level, and it needs to be based on a criteria of "sufficiently complex to be realistic but sufficiently simple to be practical", a decision that all modellers must make. 
Lastly, our model could be adapted to investigate, at the level of $R$ and $F$, the impact of multiple stressors. For example, in 2016, wildfires burnt approximately $80 \%$ of the Red Forest. There would have been, according to the dose profile used in this model, some $66 \mathrm{mGy} \mathrm{h}^{-1}$ in Zone 1 at the time. A future development of our model could therefore be the introduction of fire as a stressor. The recurrence of fires in the region presents an opportunity to revisit the area and make ecosystem restoration observations, improving the model parameterisation for this case.

\section{Conclusions}

A conceptual population model for a vole population has been developed, parameterised and applied to a Chernobyl Red Forest scenario to analyse the radiological impact of the accident at the population level. The model suggests that increased inward migration in the early phase of the accident was the main driver to restore population lost by the impact of the high levels of radiation. Newly immigrated individuals became sick but the population of healthy voles recovered steadily over about 3 years, sustained by immigration. In this situation, the repairing pool recovers more slowly than the fecundity pool. The impact of adaptation was also modelled and its effect seems to be small, but it could be a more important effect in less mobile species.

For the scenario considered, our model estimates that a migration rate constant of $255 \mathrm{~m}^{2} \mathrm{~d}^{-1}$ at 0.035 $\mathrm{Gy} \mathrm{d}^{-1}$ is a tipping point for vole population survival. A dose rate of $7-10 \mathrm{~Gy} \mathrm{~d}^{-1}$ is an additional tipping point for vole morbidity. The model predicts that a small and relatively uncontaminated area of $20 \mathrm{~km}^{2}$ with an autochthonous population of healthy voles would be able to sustain the population. We also found a tipping point for population survival if an area ratio of 1:25 or more is reached between the most contaminated patch and the total area. Historical effects of radiation are predicted, with a time delay of 1 year or more since exposure. Lastly, population level radiation effects predicted by our model are in reasonable agreement with previous field observations, migration appears to delay the onset of effects appearing at high dose rates by an order of magnitude and our model suggests that benchmark values such as the ICRP DCRLs are sufficiently protective for this case study.

This study can inform stakeholder dialogue on factors influencing population responses to radiation in the environment. Our model has the potential to aid evaluation of radiation benchmarks in multiple case studies, the effects of multiple stressors and the influence of historic doses. As such, this model is a valuable addition to the suite of modelling tools currently available to support both radioecological research and radiation protection. Furthermore, the model that we have developed has potential application in other ecological risk assessment contexts. The model allows consideration of the sensitivity of the population's key biological functions, including survival and reproduction, in the presence of ecological factors such as migration, ecosystem resource, biological adaptation and the spatial scale of a stressor (radiation in the case study that we present). The model could easily be adapted to accommodate other stressors, thereby contributing to the evaluation of other regulatory benchmarks used in non-radiological risk assessment.

\section{CRediT author statement}


803 Jordi Vives i Batlle: Conceptualisation, Methodology, Software, Validation, Formal analysis, Writing

804 - Original Draft. Writing - Review \& Editing, Supervision; Tatiana Sazykina: Conceptualisation,

805 Methodology, Validation, Writing - Review \& Editing; Alexander Kryshev: Conceptualisation,

806 Methodology, Validation, Writing - Review \& Editing; Michael D Wood: Conceptualisation,

807 Investigation, Writing - Review \& Editing, Visualisation; Karen Smith: Conceptualisation,

808 Investigation, Writing - Review \& Editing; David Copplestone: Conceptualisation, Writing - Review

809 \& Editing; Geert Biermans: Conceptualisation, Writing - Review \& Editing, Visualisation

\section{Acknowledgements}

811

812 The authors wish to thank the International Atomic Energy Agency (IAEA) for enabling us to perform

813 this work as part of the Modelling and Data for Radiological Impact Assessments (MODARIA II)

814 programme under Working group 5 - Exposure and Effects on Biota. Our thanks are extended to all

815 the members of WG5 for fruitful discussions during the project, and to the Scientific Secretary of

816 WG5 Diego Telleria, as well as the Programme Director Joanne Brown. The contribution of M.D.

817 Wood was supported by the TREE (https://tree.ceh.ac.uk/) and RED FIRE

818 (https://www.ceh.ac.uk/redfire) projects. D. Copplestone was also supported by the TREE project.

819 TREE was funded by the Natural Environment Research Council (NERC), Radioactive Waste

820 Management Ltd. and the Environment Agency as part of the Radioactivity and The Environment

821 (RATE) Programme; RED FIRE was a NERC Urgency Grant.

822

823 
Adamatzky A. ModelMaker. Kybernetes 2001; 30: 120-125.

Alonzo F, Hertel-Aas T, Real A, Lance E, Garcia-Sanchez L, Bradshaw C, et al. Population modeling to compare chronic external gamma radiotoxicity between individual and population endpoints in four taxonomic groups. Journal of Environmental Radioactivity 2016; 152: 46-59.

AnAge. The Animal Ageing and Longevity Database. A database of ageing and life history in animals, including extensive longevity records. http://genomics.senescence.info/species [Accessed 10 September 2020], 2020.

Aramrun K, Beresford NA, Skuterud L, Hevroy T, Drefvelin J, Bennett K, et al. Measuring the radiation exposure of Norwegian reindeer under field conditions. Science of the Total Environment 2019; 687: 1337-1343.

Aulak W. Production and energy requirements in a population of the Bank vole, in a deciduous forest of Circaeo-alnetum type. Acta Theriologica 1973; 18: 167-190.

Baker R J, Dickins B, Wickliffe JK, Khan FA, Gaschak S, Makova K, et al. Elevated mitochondrial genome variation after 50 generations of radiation exposure in a wild rodent. Evolutionary Applications 2017; 10: 784-791.

Beresford NA, Barnett CL, Gashchak S, Maksimenko A, Guliaichenko E, Wood MD, et al. Radionuclide transfer to wildlife at a 'Reference Site' in the Chernobyl Exclusion Zone and resultant radiation exposures. Journal of Environmental Radioactivity 2019; 211: 1-12.

Beresford NA, Gaschak S, Maksimenko A, Wood MD. The transfer of ${ }^{137} \mathrm{Cs}$, Pu isotopes and ${ }^{90} \mathrm{Sr}$ to bird, bat and ground dwelling small mammal species within the Chernobyl exclusion zone. Journal of Environmental Radioactivity 2016; 153: 231-236.

Beresford NA, Horemans N, Copplestone D, Raines KE, Orizaola G, Wood MD, et al. Towards solving a scientific controversy - The effects of ionising radiation on the environment. Journal of Environmental Radioactivity 2020a; 211: 106033.

Beresford NA, Scott EM, Copplestone D. Field effects studies in the Chernobyl Exclusion Zone: Lessons to be learnt. Journal of Environmental Radioactivity 2020b; 211: 105893.

Bird WA, Little JB. A Tale of Two Forests: Addressing Postnuclear Radiation at Chernobyl and Fukushima Environmental Health Perspectives 2013; 121: a78-a85.

Boratyński Z, P. K. The association between body mass, metabolic rates and survival of bank voles. Functional Ecology 2009; 23: 330-339.

Borowski Z. Habitat selection and home range size of field voles Microtus agrestis in Sowiñski National Park, Poland. Acta Theriologica 2003; 48: 325-333.

Borowski Z, Owadowska E. Field vole (Microtus agrestis) seasonal spacing behavior: the effect of predation risk by mustelids. Naturwissenschaften 2010; 97: 487-493.

Bradshaw C, Kapustka L, Barnthouse L, Brown J, Ciffroy P, Forbes V, et al. Using an ecosystem approach to complement protection schemes based on organism-level endpoints. Journal of Environmental radioactivity 2014; 136: 98-104.

Brechignac FD, M. Challenging the current strategy of radiological protection of the environment: arguments for an ecosystem approach. Journal of Environmental Radioactivity 2009; 100 : 1125-1134.

Brown JE, Alfonso B, Avila R, Beresford N, Copplestone D, Hosseini A. A new version of the ERICA tool to facilitate impact assessments of radioactivity on wild plants and animals. Journal of Environmental Radioactivity 2016; 153: 141-149.

Brown JE, Alfonso B, Avila R, Beresford NA, Copplestone D, Pröhl G, et al. The ERICA Tool. Journal of Environmental Radioactivity 2008; 99: 1371-1383.

Bytwerk DP. An Allometric Examination of the Relationship Between Radiosensitivity and Mass. Msc Thesis, Oregon State University, $70 \mathrm{pp}$. http://ir.library.oregonstate.edu/jspui/handle/1957/7688 [Accessed 10 September 2020], 2006. 
Chesser RK, Sugg DW, Lomakin MD, Van Den Bussche RA, Dewoody JA, Jagoe CH, et al. Concentrations and dose rate estimates of ${ }^{134,137}$ cesium and ${ }^{90}$ strontium in small mammals at Chornobyl, Ukraine. Environmental Toxicology and Chemistry 2000; 19: 305-312.

Deryabina TG, Kuchmel SV, Nagorskaya LL, Hinton TG, Beasley JC, Lerebours A, et al. Long-term census data reveal abundant wildlife populations at ChernobyL. Current Biology 2015; 25: R824-R826.

Doi M, Kawaguchi I, Tanaka N, Fuma S, Ishii N, Miyamoto K, et al. Model ecosystem approach to estimate community level effects of radiation. Radioprotection 2005; 40: S913-S919.

EOL. Bank Vole. In: Encyclopedia of Life. http://eol.org/pages/1179604/ [Accessed 10 September 2020], 2020.

Forbes VE, Calow P. Population growth rate as a basis for ecological risk assessment of toxic chemicals. Philosophical Transactions of the Royal Society B-Biological Sciences 2002; 357: 1299-1306.

Galic N, Hommen U, Hans Baveco JM, Van Den Brink PJ. Potential application of population models in the European ecological risk assessment of chemicals. II. Review of models and their potential to address environmental protection aims. Integrated Environmental Assessment and Management 2010; 6: 338-360.

Gaschak SP, Maklyuk YA, Maksimenko AM, Bondarkov MD, Jannik GT, Farfán EB. Radiation ecology issues associated with murine rodents and shrews in the Chernobyl exclusion zone. Health Physics 2011; 101: 416-430.

Gaychenko VA. ${ }^{137} \mathrm{Cs}$ migration in the pasture type trophic chain. In: Ecologo-fauna studies in the ChNPP area. UkrRNPF Meditsina-Ecologiya 1995: 3-17.

Geraskin S, Fesenko SV, Alexakhin RM. Effects of non-human species irradiation after the Chernobyl NPP accident. Environment International 2008; 34: 880-897.

Glorvigen P. Vole population cycles and the role of colonisation. A dissertation for the degree of Philosophiae Doctor, University of Troms $\emptyset$, September 2012. https://munin.uit.no/bitstream/handle/10037/4655/thesis.pdf?sequence=2, 2012.

Goncharova RI, Ryabokon NI, Smolic hIl. Biological effects of low-dose chronic irradiation in somatic cells of small mammals. In: Gossens LHJ, ed. Risk analysis: facing the new millennium. Proceedings of 9th Annual Conference. Rotterdam: Delft University Press, pp. 710-714. 1999.

Hanson N, Stark JD. Utility of population models to reduce uncertainty and increase value relevance in ecological risk assessments of pesticides: an example based on acute mortality data for daphnids. Integrated Environmental Assessment and Management 2011; 8: 262-270.

Hansson L. Sex Ratio in Small Mammal Populations as Affected by the Pattern of Fluctuations. Acta Theriologica 1978; 23: 203-212.

Hutterer R, Kryštufek B, Yigit N, Mitsain G, Palomo L, Henttonen H, et al. Myodes glareolus. The IUCN Red List of Threatened Species 2016: e.T4973A115070929. http://dx.doi.org/10.2305/IUCN.UK.2016-3.RLTS.T4973A22372716.en [Accessed 10 September 2020], 2016.

IAEA. Effects of ionising radiation on plants and animals at levels implied by current radiation protection standards. Technical Report Series No 332, International Atomic Energy Agency, Vienna, 1992.

Ibrahim L, Preuss TG, Schaeffer A, Hommen U. A contribution to the identification of representative vulnerable fish species for pesticide risk assessment in Europe e a comparison of population resilience using matrix models. Ecological modelling 2014; 280: 65-75.

ICRP. Environmental Protection: The Concept and use for Reference Animals and Plants.International Commission on Radiological Protection Publication 108, Annals of the ICRP 38(4-6), Elsevier Ltd., 76 pp, 2008.

Jedrzejewska B, Jedrzejewski W. Predation in vertebrate communities. The Białowieża Primeval Forest as a case study. Springer Verlag, Berlin-Heidelberg-New York: 1-450. 1998. 
Klemola T, Korpimäki E, Norrdahl K, Tanhuanpaa M, Koivula M. Mobility and habitat utilization of small mustelids in relation to cyclically fluctuating prey abundances. Annales Zoologici Fennici 1999; 36: 75-82.

Koivula M, Korpimäki E. Do Scent Marks Increase Predation Risk of Microtine Rodents. Oikos 2001; 95: 275-281.

Krueger S, Joiner M, Weinfeld M, Piasentin E, Marples B. Role of apoptosis in low-dose hyperradiosensitivity. Radiation research 2007; 167: 260-267.

Kryshev Al, Ryabov IN. A dynamic model of ${ }^{137} \mathrm{Cs}$ accumulation by fish of different age classes. Journal of Environmental Radioactivity 2000; 50: 221-233.

Kryshev Al, Sazykina TG. Modelling the effects of ionizing radiation on survival of animal population: acute versus chronic exposure. Radiation and Environmental Biophysics 2015; 54: 103-109.

Kryshev AI, Sazykina TG, Badalian KD. Mathematical simulation of dose-effect relationships for fish eggs exposed chronically to ionizing radiation. Radiation and Environmental Biophysics 2006; 45: 195-201.

Kryshev AI, Sazykina TG, Sanina KD. Modelling of effects due to chronic exposure of a fish population to ionizing radiation. Radiation and Environmental Biophysics 2008; 47: 121-129.

Kryshev II, Sazykina TG, Beresford NA. Effects on Wildlife. In: J. Smith and N.A. Beresford (Eds.), Chernobyl: Catastrophe and Consequences, Springer - Praxis Books in Environmental Sciences, Praxis Publishing, Chichester (UK), pp. 267-287, 2005.

Kryštufek B, Vohralík V, Zima J, Zagorodnyuk I. Microtus agrestis (errata version published in 2017). The IUCN Red List of Threatened Species 2016: e.T13426A115112050. https://dx.doi.org/10.2305/IUCN.UK.2016-3.RLTS.T13426A22349665.en. [Accessed 10 September 2020], 2008.

Lehmann P, Boratyński Z, Mappes T, Mousseau TA, Møller AP. Fitness costs of increased cataract frequency and cumulative radiation dose in natural mammalian populations from Chernobyl. Scientific Reports 2016; 6: 1-7.

Lotka A. Elements of Physical Biology. Baltimore: Williams and Wilkins, 460 pp, 1925.

MacDonald D. The Encyclopedia of Mammals: Andromeda Oxford Limited, 2001.

Meeks HN, Wickliffe JK, Hoofer SR, Chesser RK, Rodgers BE, Baker RJ. Mitochondrial control region variation in bank voles (Clethrionomys glareolus) is not related to Chernobyl radiation exposure. Environmental Toxicology and Chemistry 2007; 26: 361-369.

Møller AP, Mousseau TA. Are organisms adapting to ionizing radiation at Chernobyl? Trends in Ecology \& Evolution 2016; 31: 281-289.

Monte L. Predicting the effects of ionising radiation on ecosystems by a generic model based on the Lotka-Volterra equations. Journal of Environmental Radioactivity 2009; 100: 477-483.

Mustonen V, Kesäniemi J, Lavrinienko A, Tukalenko E, Mappes T, Watts PC, et al. Fibroblasts from bank voles inhabiting Chernobyl have increased resistance against oxidative and DNA stresses. BMC Molecular and Cell Biology 2018; 19: 1-10.

Myllymäki A. Interspecific competition and home range dynamics in the field vole Microtus agrestis. Oikos 1977; 29: 553-569.

Pomerantseva MD, Ramaya LK, A.V. R, Shevchenko VA. Genetic consequences of increased radiation background for murine rodents. Radiatsionnaia biologiia, radioecologiia 2006; 46: 279-286.

Pryakhin EA, Shvedov VL, Akleev AV. Assessments of effects of dose rates and absorbed doses on long-term radiation related consequences for rats associated with the chronic ${ }^{90} \mathrm{Sr}$ intake. Journal of Radiation Biology and Radioecology 2002; 42: 412-418.

Real A, Sundell-Bergman S, Knowles JF, Woodhead DS, Zinger I. Effects of ionising radiation exposure on plants, fish and mammals: relevant data for environmental radiation protection. Journal of Radiological Protection 2004; 24: A123-A137.

Rigas ML. Software Review: Modelmaker 4.0. Risk Analysis 2000; 20: 543-544.

Rodgers BE, Baker RJ. Frequencies of micronuclei in Bank voles from zones of high radiation at Chornobyl, Ukraine. Environmental Toxicology and Chemistry 2000; 19: 1644-1648. 
Ryabokon NI, Goncharova RI. Transgenerational accumulation of radiation damage in small mammals chronically exposed to Chernobyl fallout. Radiation and Environmental Biophysics 2006; 45: 167-177.

Sazykina T. Population sensitivities of animals to chronic ionizing radiation-model predictions from mice to elephant. Journal of Environmental Radioactivity 2018; 182: 177-182.

Sazykina T, Kryshev A. Simulation of population response to ionizing radiation in an ecosystem with a limiting resource e Model and analytical solutions. Journal of environmental radioactivity 2016; 151: 50-57.

Sazykina T, Kryshev II. Radiation effects in wild terrestrial vertebrates - the EPIC collection. Journal of Environmental Radioactivity 2006; 88: 11-48.

Sazykina TG, Kryshev Al. Radiation effects in generic populations inhabiting a limiting environment. Radiation and Environmental Biophysics 2012; 51: 215-221.

Sazykina TG, Kryshev II. Effects of ionising radiation on terrestrial animals: Dose-effects relationships. In: Proc. International conference on the Protection of the Environment from the Effects of Ionizing Radiation. Contributed papers. Stockholm, Sweden 6-10 October 2003, pp. 95-97, 2003.

Short S, Mayes C, Woodcock M, Johns H, Joiner MC. Low dose hypersensitivity in the T98G human glioblastoma cell line. International journal of radiation biology 1999a; 75: 847-855.

Short SC, Mitchell SA, Boulton P, Woodcock M, Joiner MC. The response of human glioma cell lines to low-dose radiation exposure. International Journal of Radiation Biology 1999b; 75: 13411348.

Sokolov VE, Ryabov IN, Ryabtsev IA, Kulikov AO, Tichomirov FA, Sheheglov AI. Effects of radioactive contamination on the flora and fauna in the vicinity of Chernobyl nuclear power plant. In: T.M. Turpaev (Ed.). Soviet scientific reviews, Section F, physiology and general biology reviews. Newark, NJ: Harwood Academic Publishers GmbH, pp. 1-124, 1994.

Spitzenberger F. Clethrionomys glareolus. In: A. J. Mitchell-Jones, G. Amori, W. Bogdanowicz, B. Kryštufek, P. J. H. Reijnders, F. Spitzenberger, M. Stubbe, J. B. M. Thissen, V. Vohralík and J. Zima (eds), The Atlas of European Mammals, Academic Press, London, UK, 1999.

Stark JD, Banks JE, Vargas R. How risky is risk assessment? the role that life history strategies play in susceptibility of species to pesticides and other toxicants. Proceedings of the National Academy of Sciences of the United States of America 2004; 101: 732-736.

Stenseth NC, Viljugrein H, Jedrzejewski W, Mysterud A, Pucek Z. Population dynamics of Clethrionomys glareolus and Apodemus flavicollis: seasonal components of density dependence and density independence. Acta Theriologica 2002; 47: 39-67.

Sundell J. Vole population dynamics: experiments on predation. Academic dissertation, University of Helsinki, Finland. https://citeseerx.ist.psu.edu/viewdoc/download?doi=10.1.1.617.1353\&rep=rep1\&type=pdf [Accessed 10 September 2020], 2002.

Suschenya LM, Pikulik MM, Plenina AE. Animal world in the area of the Chernobyl NPP accident. Minsk: Nauka i tekhnika 1995: 263.

Suschenya LM, Pikulik MM, Plenina AE. Assessment of radiobiological consequences in the fauna of the Chernobyl NPP accident. In: E.V. Senin (Ed.), Proc. $1^{\text {st International Conference: Biological }}$ and Radioecological Aspects of Consequences of the Chernobyl NPP Accident. Radioecology of plants. Radioecology of terrestrial animals. Radioecology of hydrobionts. Zeleny Mys 1990: 137-159., 1990.

Testov BV, Taskaev Al. Dynamics of mouse-type rodent populations in the zone of the Chernobyl NPP. In: Ryabov, I.N. and Ryabtsev, I.A. (eds), Biological and Radio-ecological Aspects of the Consequences of the Chernobyl Accident, p. 86. Abstracts of the 1st International Conference ('Zeleny Mys', 10-18 September, 1990). USSR Academy of Sciences, Moscow, 1990.

Torre I, Arrizabalaga A. Habitat preferences of the bank vole Myodes glareolus in a Mediterranean mountain range Acta Theriologica 2008; 53: 241-250. 
Verhulst P-F. Notice sur la loi que la population poursuit dans son accroissement. Correspondance Mathématique et Physique 1838; 10: 113-121.

Verhulst P-F. Recherches mathématiques sur la loi d'accroissement de la population. Nouveaux Mémoires de l'Académie Royale des Sciences et Belles-Lettres de Bruxelles 1845; 18: 1-42.

Vives i Batlle J. Dual age class population model to assess radiation dose effects to non-human biota populations. Radiation and Environmental Biophysics 2012; 51: 225-243.

Vives i Batlle J, Sazykina T, Kryshev A, Monte L, Kawaguchi I. Inter-comparison of population models for the calculation of radiation dose effects to wildlife. Radiation and Environmental Biophysics 2012; 51: 399-410.

Wereszczyńska AM, Nowakowski WK, Nowakowski JK, Jędrzejewska B. Is food quality responsible for the cold-season decline in bank vole density? Laboratory experiment with herb and acorn diets. Folia Zoologica 2007; 56: 23-32.

Whicker FW, Schultz V. Radioecology: Nuclear Energy and the environment. Vol. 1. CRC press, Inc. Boca Raton, Florida. 1982a.

Whicker FW, Schultz V. Radioecology: Nuclear Energy and the environment. Vol. 2. CRC press, Inc. Boca Raton, Florida, 1982b.

Wilson RC, Vives i Batlle J, Watts SJ, McDonald P, Jones SR, Vives-Lynch SM, et al. Approach to the assessment of risk from chronic radiation to populations of phytoplankton and zooplankton. Radiation and Environmental Biophysics 2010; 49: 87-95.

Wodarz D, Sorace R, Komarova NL. Dynamics of Cellular Responses to Radiation. PLOS Computational Biology 2014; 10: 1-11.

Wood MD, Beresford NA, Barnett CL, Copplestone D, Leah RT. Assessing radiation impact at a protected coastal sand dune site: An intercomparison of models for estimating the radiological exposure of non-human biota. Journal of Environmental Radioactivity 2009; 100 : 1034-1052. 


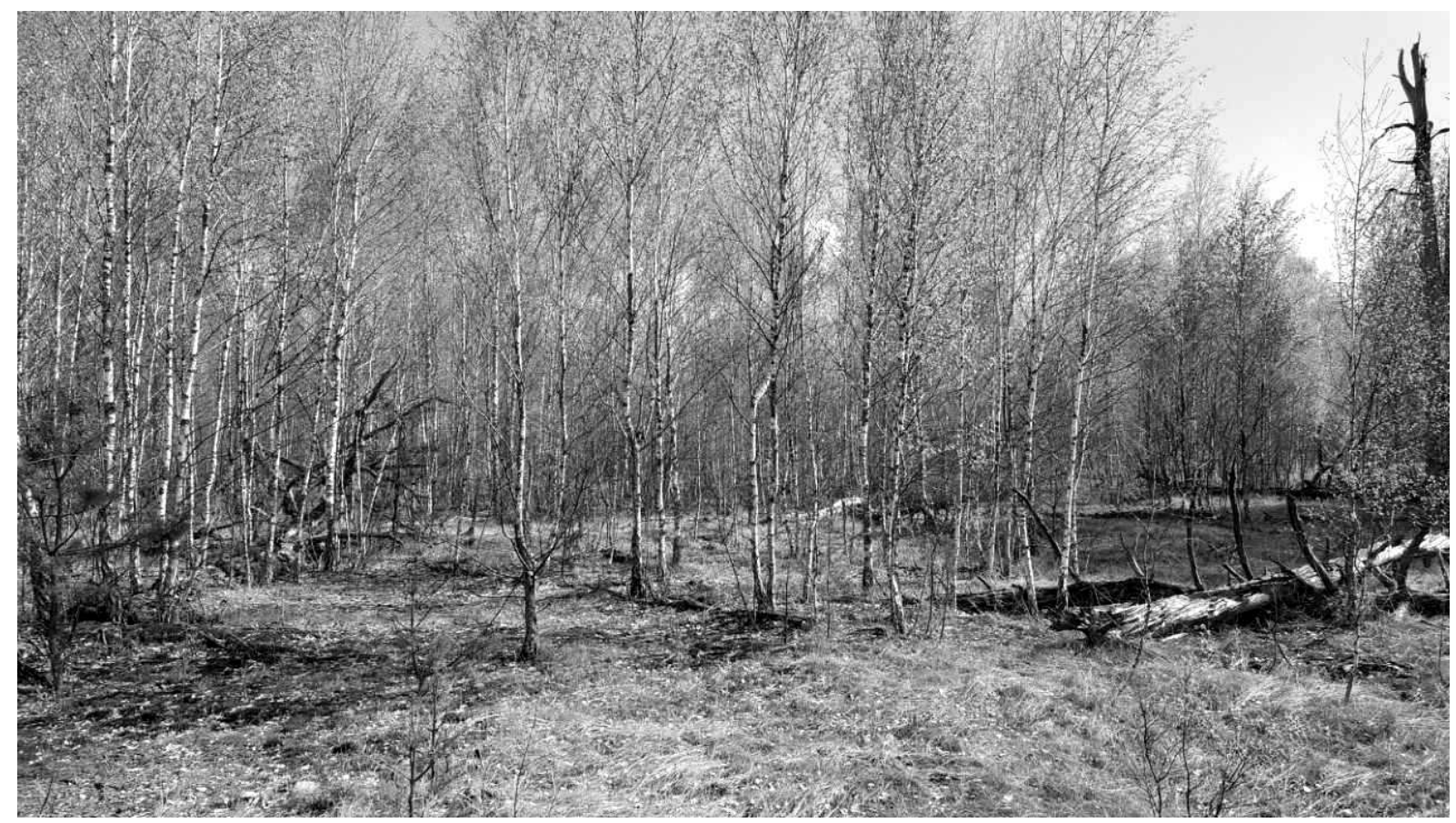

Figure 1: The Red Forest in April 2016, just before the 2016 fire, showing the remains of dead pine trees lying on the ground, the deciduous trees that replaced them and some pines attempting to grow in the foreground. The grass, moss and lichen ground cover are also visible. 


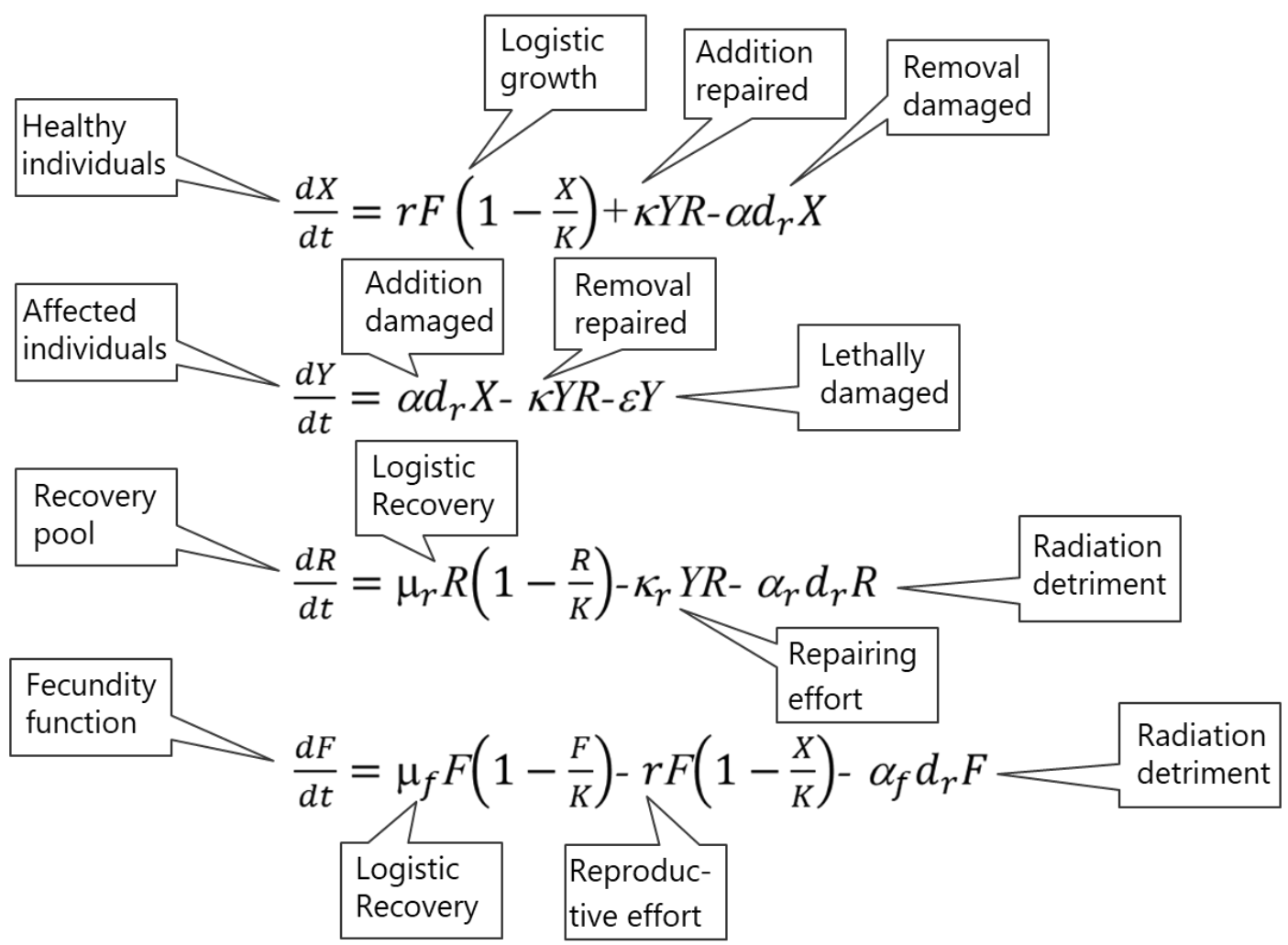

Figure 2: Equations governing the exchange between healthy $(X)$ and sick $(Y)$ members of the population, their recovery pool $R$ and the fecundity $F$. Symmetry considerations demand that $\mu_{f}=r$ (Vives i Batlle, 2012). 


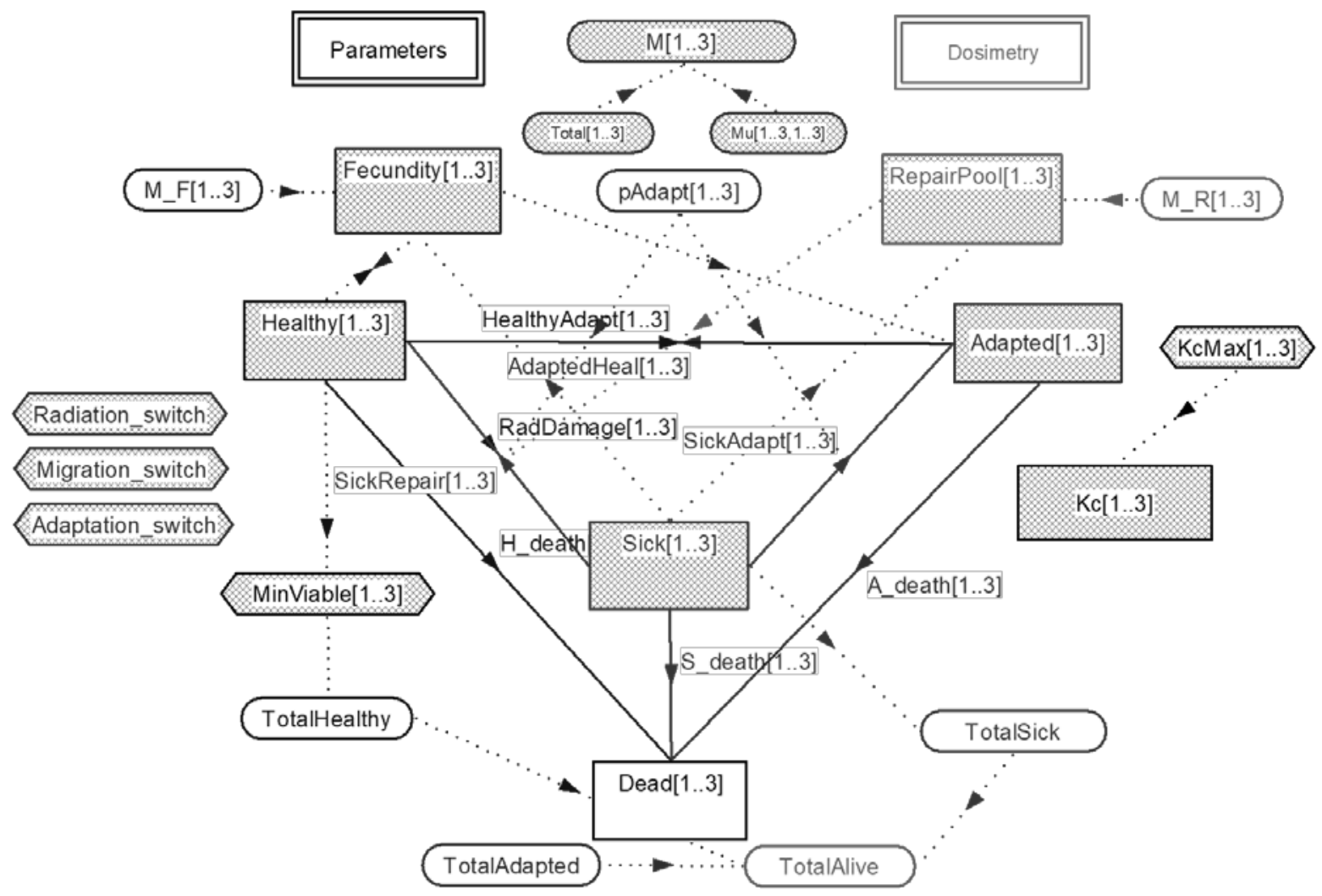

Figure 3: Model in ModelMaker 4. The indices 1-3 describe the three patches. Notation: Rectangles are compartments, rounded rectangles are variables, hexagonal rectangles are definitions, arrows are flows and dotted arrows are influences. 


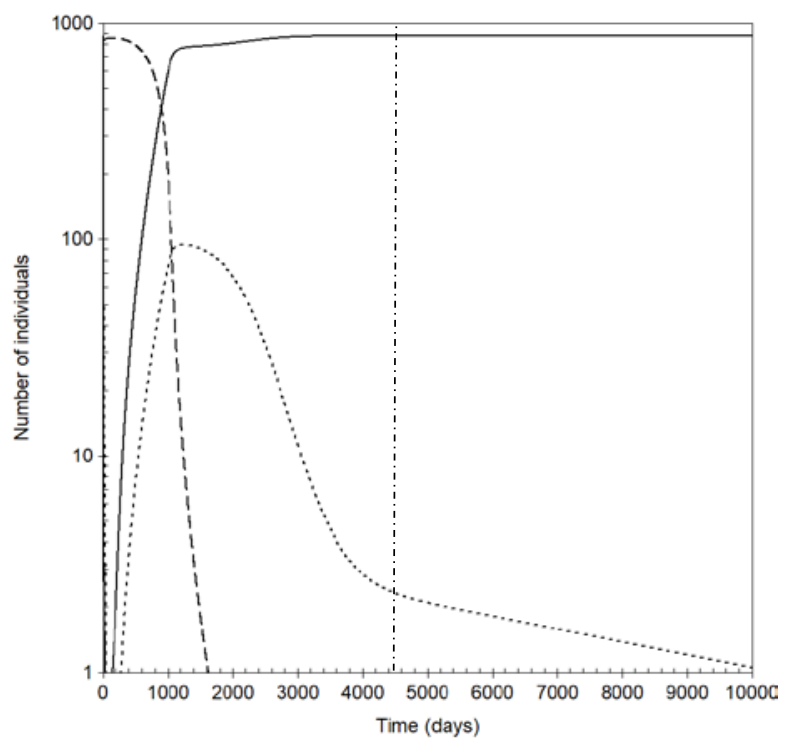

(a) Region 1- all processes

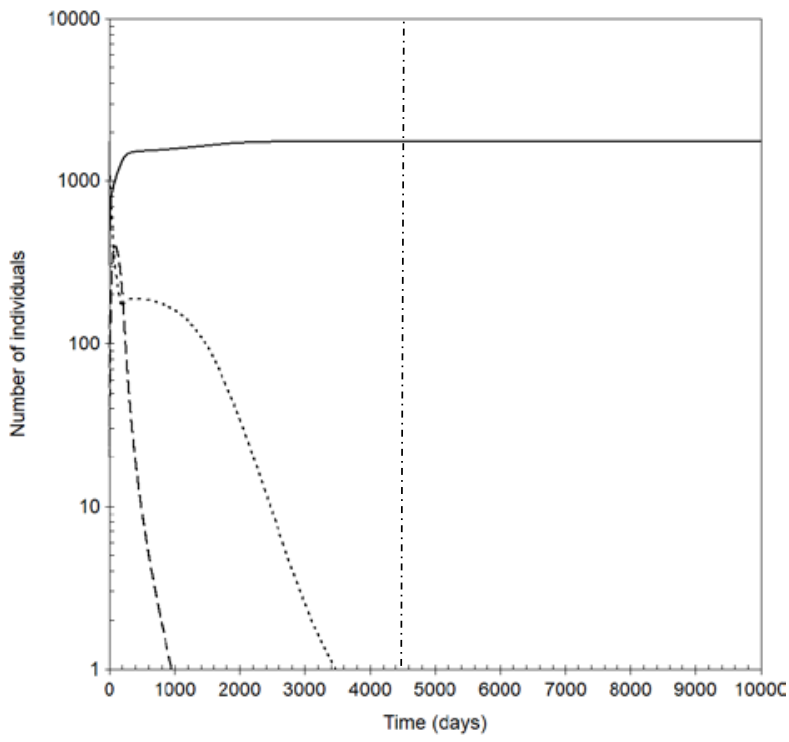

(c) Region 2 - all processes

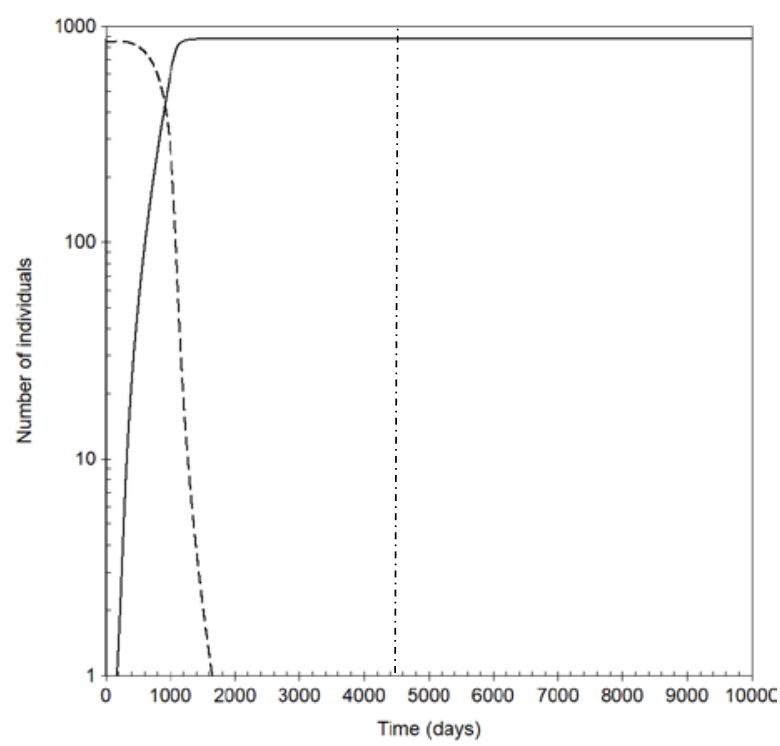

(b) Region 1- no adaptation

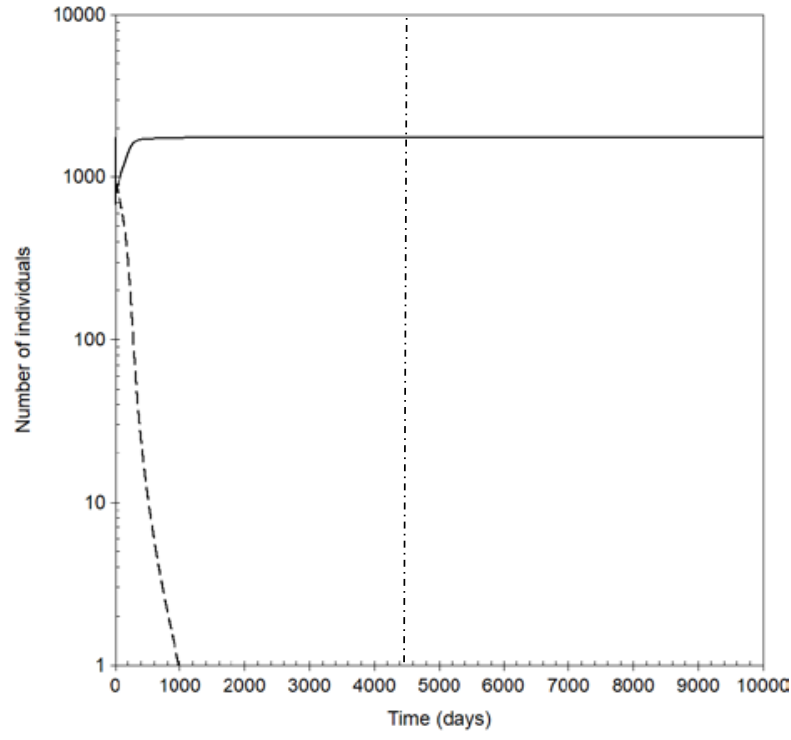

(d) Region 2 - no adaptation

Figure 4: Model simulations of $X$ (solid line), $Y$ (dashed line) and $W$ (dotted line) voles. The vertical line at $4500 \mathrm{~d}$ in this and subsequent figures is the transition point $T_{S}$ where long-lived radionuclides dominate the dose. 


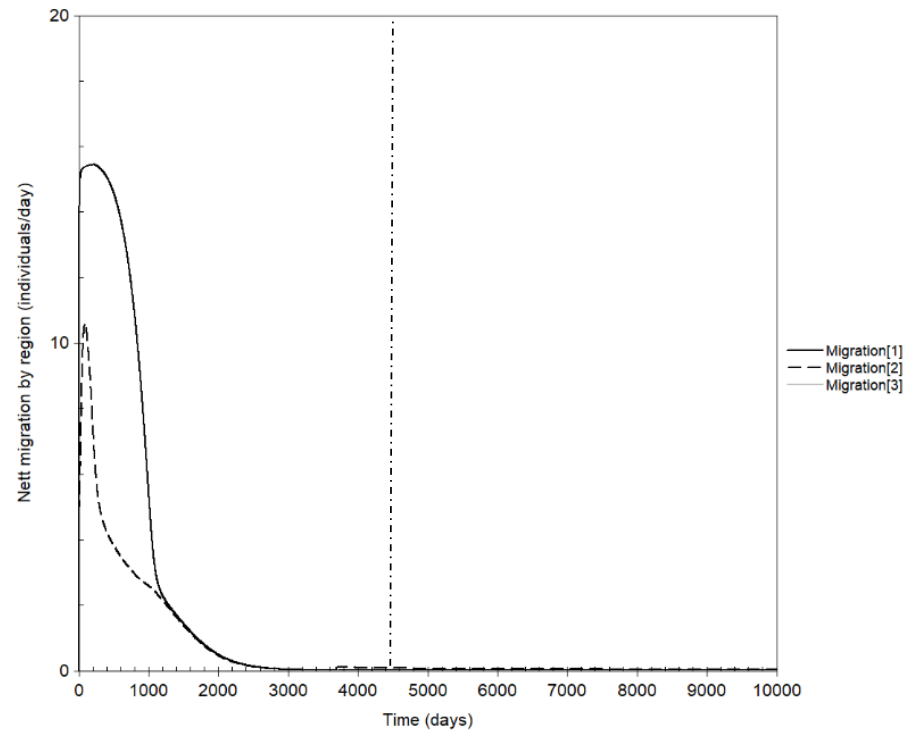

Figure 5: Migration fluxes for the different patches 


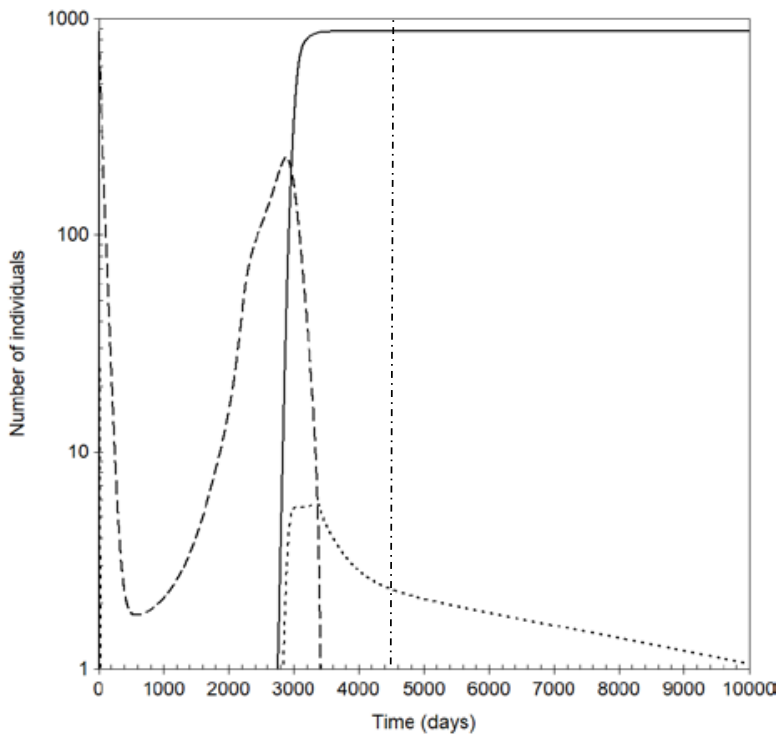

(a) Region 1, migration rate $=290 \mathrm{~m}^{2}$ day $^{-1}$

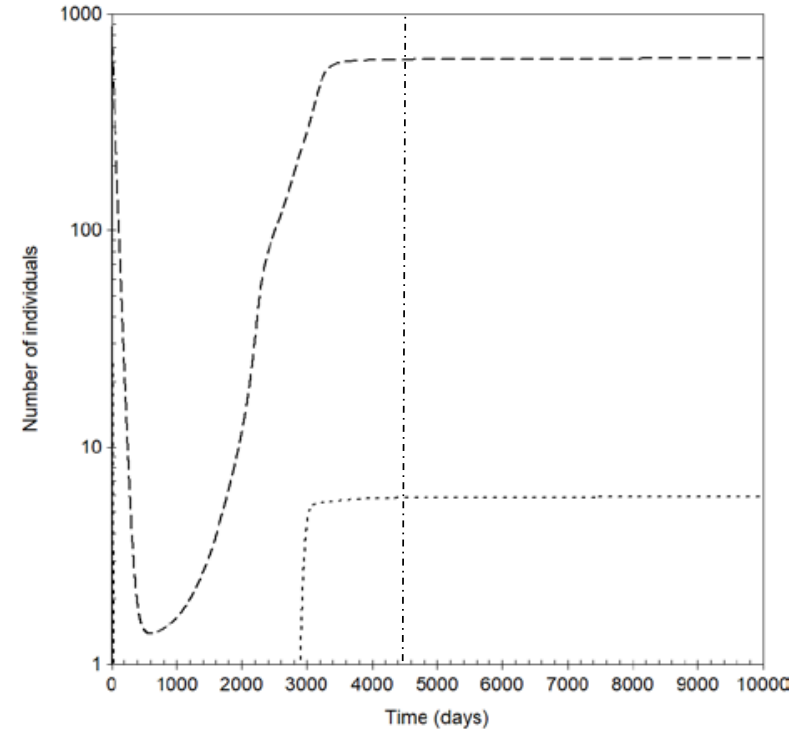

(b) Region 1, migration rate $=255 \mathrm{~m}^{2}$ day $^{-1}$

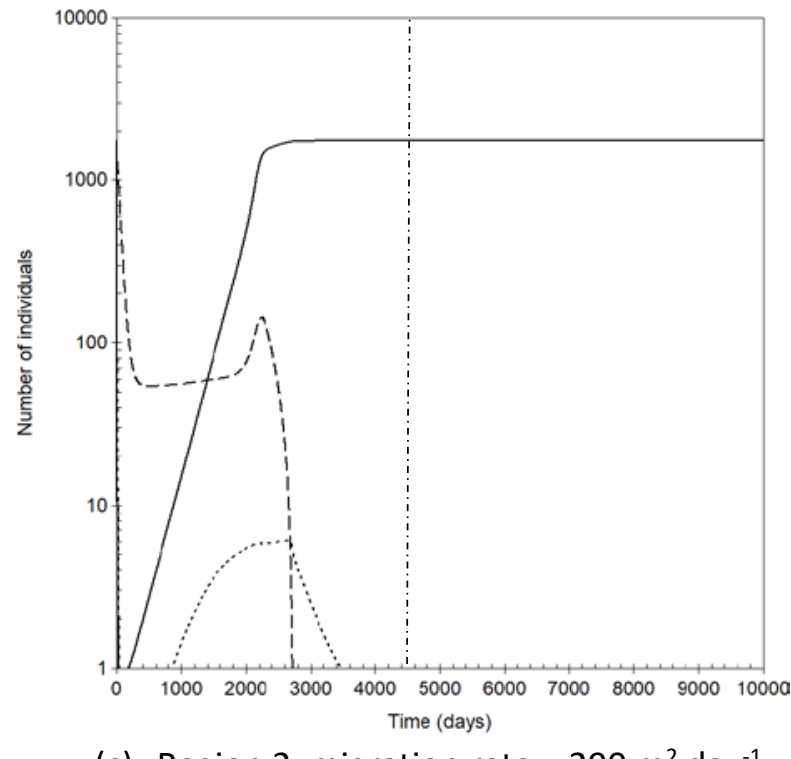

(c) Region 2, migration rate $=290 \mathrm{~m}^{2}$ day $^{-1}$

Figure 6: Model simulations of $X$ (solid line), $Y$ (dashed line) and $W$ (dotted line) voles, illustrating the result of reducing the migration rate from $290 \mathrm{~m}^{2}$ day $^{-1}$ to $255 \mathrm{~m}^{2}$ day $^{-1}$, chosen for being close to the point at which $X$ disappears. 


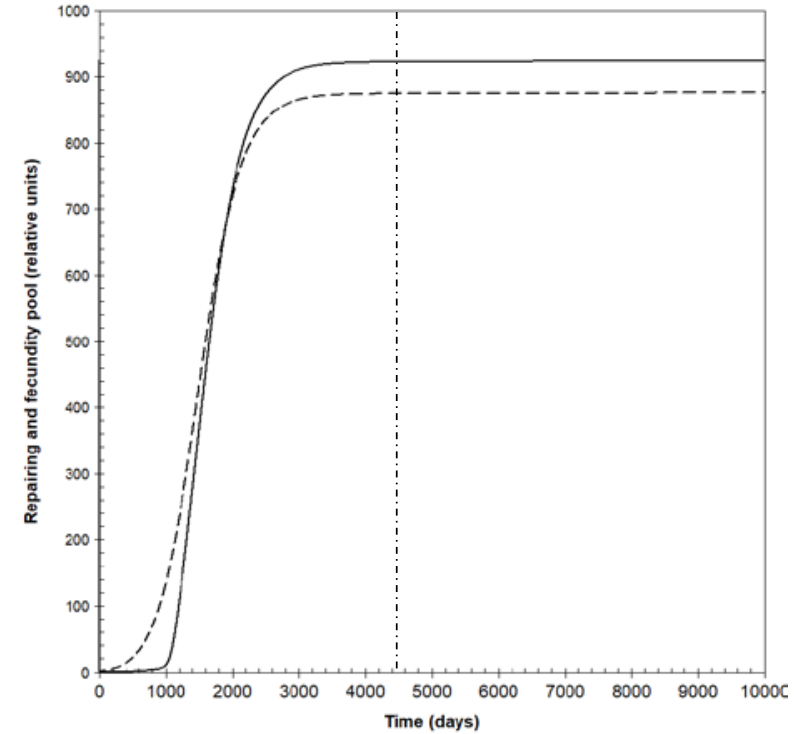

(a) Region 1

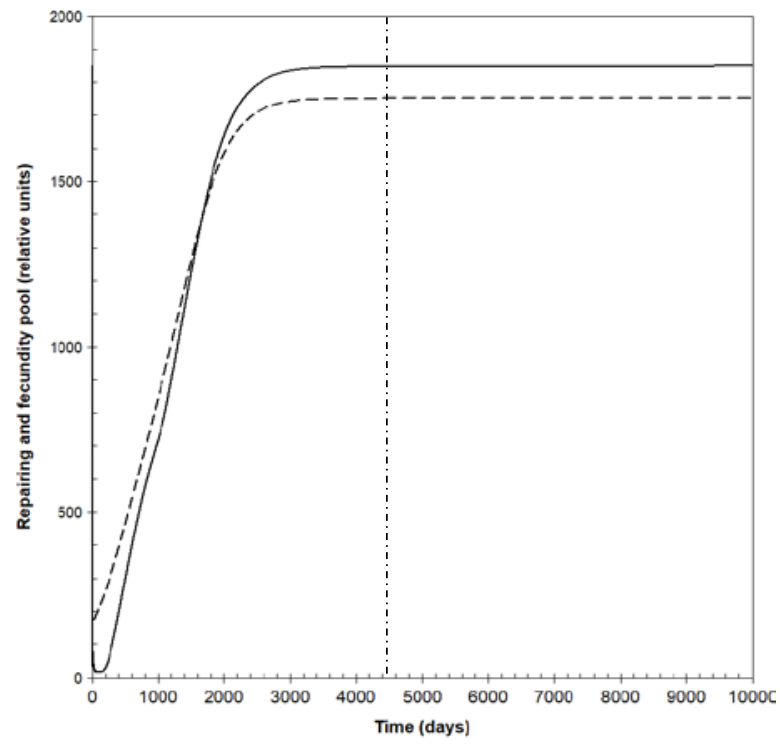

(b) Region 2

Figure 7: Model simulation of $R$ (solid line) and $F$ (dashed line), with all processes included 

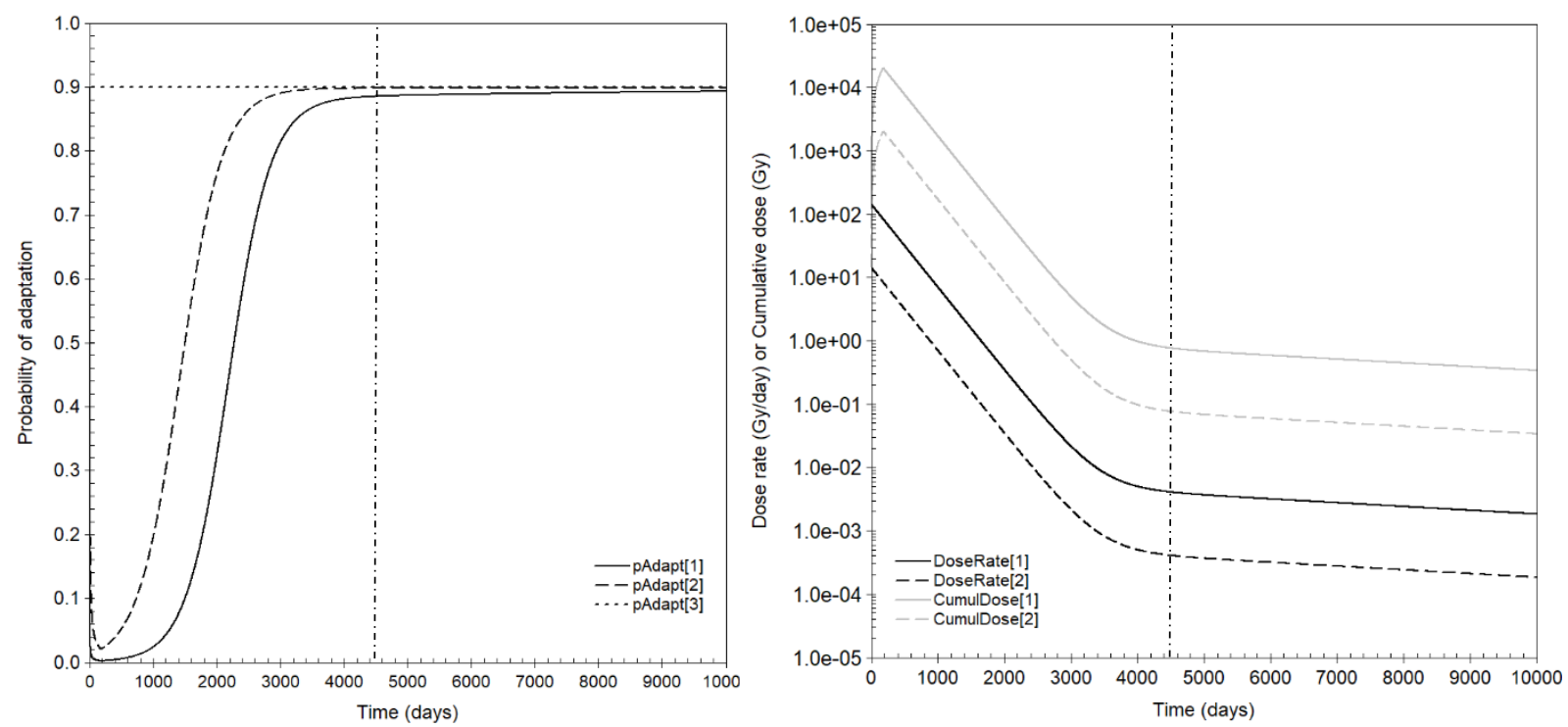

Figure 8: Probability of adaptation (left) and dose rates (black) plus cumulative doses (grey) (right). The data correspond to Regions 1 (solid), 2 (dashed) and 3 (dotted), respectively. 

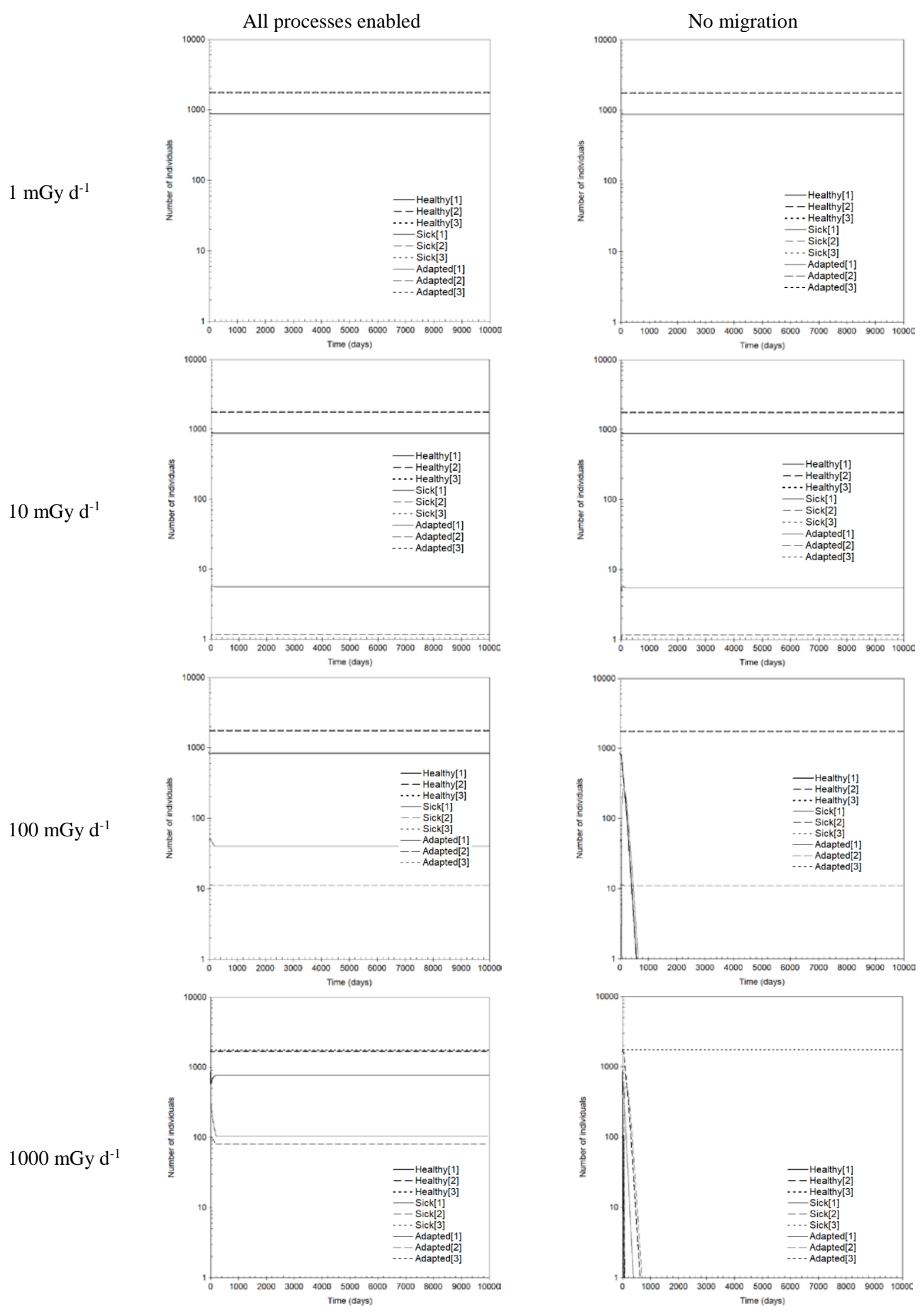

Figure 9: Model simulations of population with varying levels of dose rate in Region 1, assumed constant in time 

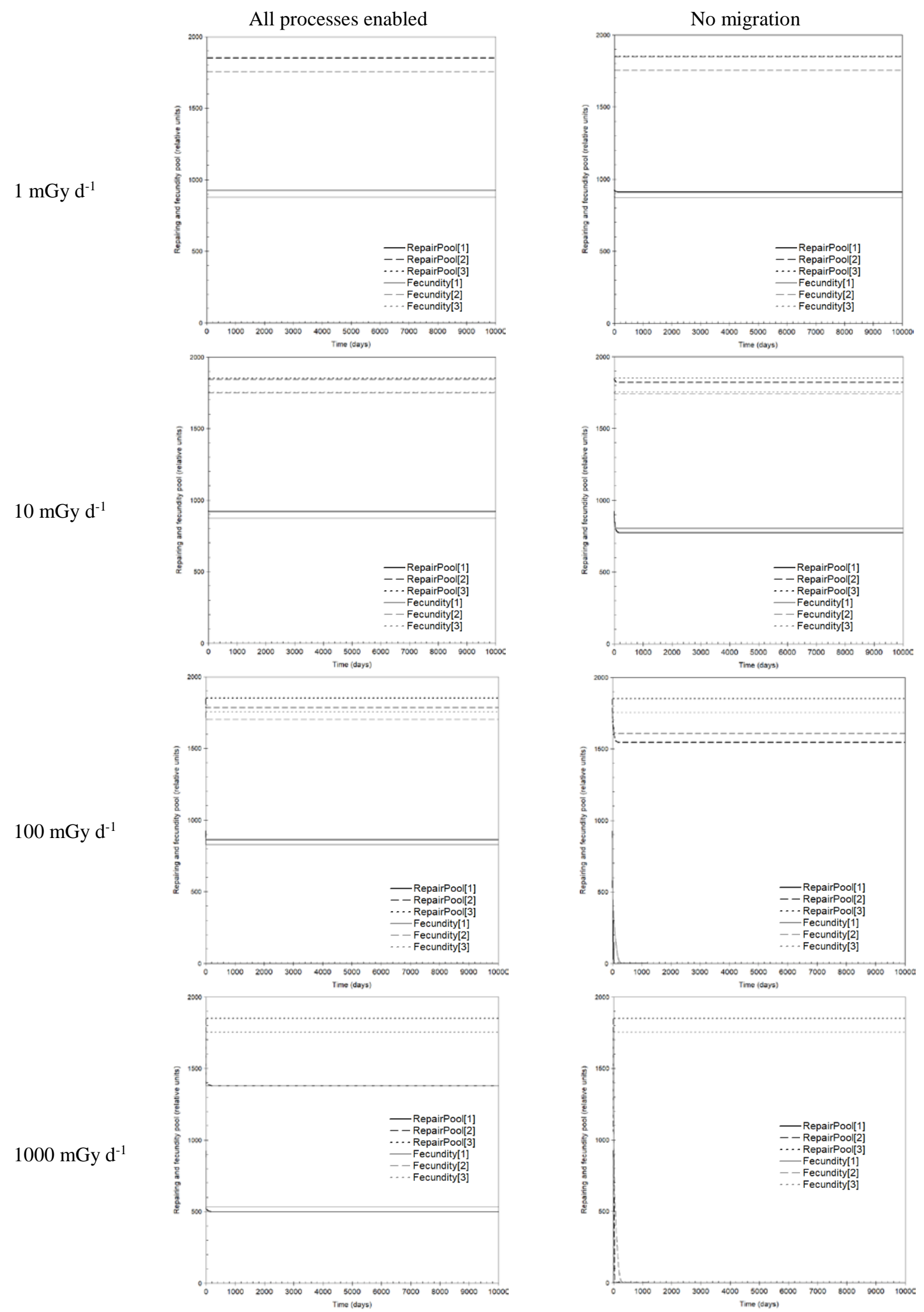

Figure 10: Model simulations of repairing pool and fecundity with varying levels of dose rate in Region 1, assumed constant in time 


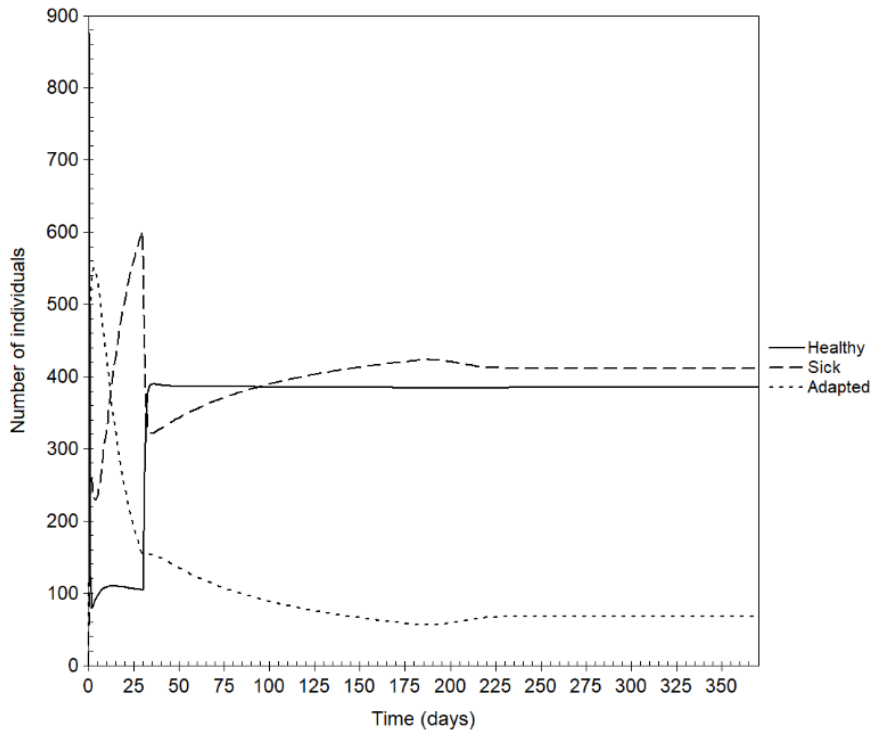

Figure 11: Simulation with dose rate step function of $25 \mathrm{~Gy} \mathrm{~d}^{-1}$ for $\mathrm{T}<30 \mathrm{~d}$ and $10 \mathrm{~Gy} \mathrm{~d}^{-1}$ for $\mathrm{T} \geq 30 \mathrm{~d}$ 
Table 1: Parameter values for the model

\begin{tabular}{|c|c|c|c|c|}
\hline Parameter & Description & Units & Value & Reference \\
\hline \multicolumn{5}{|c|}{$\underline{\text { Radiobiological parameters }}$} \\
\hline$\alpha$ & Radiation damage & $\mathrm{Gy}^{-1}$ & 0.11 & $\begin{array}{l}\text { Calculated from } L D_{50 / 30} \text { of } 6.2 \mathrm{~Gy} \text { for } \\
\text { mouse (Sazykina and Kryshev, 2016) }\end{array}$ \\
\hline$\alpha_{\mathrm{r}}$ & Repairing pool damage & $\mathrm{Gy}^{-1}$ & 0.4 & (Sazykina and Kryshev, 2016) \\
\hline$\alpha_{\mathrm{f}}$ & Fecundity pool damage & $\mathrm{Gy}^{-1}$ & 0.45 & $\begin{array}{l}\text { Based on dose for sterility > 4Gy } \\
\text { (Sazykina and Kryshev, 2016) }\end{array}$ \\
\hline$\varepsilon$ & Lethality rate & day $^{-1}$ & 0.015 & $\begin{array}{l}\text { (Sazykina and Kryshev, 2016) (from } \\
\text { dose data for total lethality) }\end{array}$ \\
\hline$\kappa$ & Output of repairing process rate $\left(\kappa / \kappa_{\mathrm{r}}<1\right)$ & day $^{-1}$ & 0.2 & $\begin{array}{l}\text { Derived from metabolic rate (Sazykina } \\
\text { and Kryshev, 2016) }\end{array}$ \\
\hline$\kappa_{\mathrm{r}}$ & Non-lethal damages recovery & day $^{-1}$ & 0.21 & $\begin{array}{l}\text { Derived from metabolic rate (Sazykina } \\
\text { and Kryshev, 2016) }\end{array}$ \\
\hline$\mu_{\mathrm{r}}$ & $\begin{array}{l}\text { Damaged individuals repair (repair pool auto- } \\
\text { recovery rate constant) }\end{array}$ & day $^{-1}$ & 0.032 & $\begin{array}{l}\text { From published information (Sazykina, } \\
\text { 2018) }\end{array}$ \\
\hline $\mathrm{p}_{0}$ & $\begin{array}{l}\text { Coefficient for saturation function controlling } \\
\text { adaptation probability }\end{array}$ & Unit-less & 0.11 & $\begin{array}{l}\text { From published information (Wodarz } \\
\text { et al., 2014) }\end{array}$ \\
\hline $\mathrm{p}_{1}$ & $\begin{array}{l}\text { Coefficient for saturation function controlling } \\
\text { adaptation probability }\end{array}$ & $\mathrm{Gy}^{-1}$ & 0.023 & $\begin{array}{l}\text { From published information (Wodarz } \\
\text { et al., 2014) }\end{array}$ \\
\hline$\eta$ & Conversion of adapted organisms to healthy & day $^{-1}$ & 0.15 & Model calibration \\
\hline \multicolumn{5}{|c|}{ Ecological parameters } \\
\hline $\mathrm{Lv}$ & Vole lifespan & day & 180.5 & $\begin{array}{l}\text { From published information } \\
\text { (MacDonald, 2001) }\end{array}$ \\
\hline d & $\begin{array}{l}\text { Death (combining natural death and } \\
\text { predation) }\end{array}$ & day $^{-1}$ & 0.0031 & $\begin{array}{l}\text { AnAge database (see (Sazykina and } \\
\text { Kryshev, 2016)) }\end{array}$ \\
\hline r & Reproduction (fecundity pool auto-recovery) & day $^{-1}$ & 0.06 & $\begin{array}{l}\text { From published information } \\
\text { (Glorvigen, 2012) }\end{array}$ \\
\hline$\rho$ & Vole population density & $\mathrm{m}^{-2}$ & 0.037 & $\begin{array}{l}\text { From published information (Aulak, } \\
\text { 1973) }\end{array}$ \\
\hline$v$ & Vegetation damage & day $^{-1}$ & 0.036 & See Section 3.1. \\
\hline$\sigma$ & Vegetation recovery & day $^{-1}$ & 0.0164 & See Section 3.1. \\
\hline$\mu_{\mathrm{ij}}$ & Elements of the migration rate matrix & $m^{2} d^{-1}$ & $3.7 \times 10^{5}$ & See Section 3.2. \\
\hline
\end{tabular}

